\title{
Smoking and reproduction: The oviduct as a target of cigarette
} smoke

\author{
Prue Talbot* and Karen Riveles
}

Address: Department of Cell Biology and Neuroscience, Interdepartmental Graduate Program in Environmental Toxicology, University of California, Riverside, CA 92521, USA

Email: Prue Talbot* - talbot@ucr.edu; Karen Riveles - karenriv@aol.com

* Corresponding author

Published: 28 September 2005

Reproductive Biology and Endocrinology 2005, 3:52 doi:10.1186/1477-7827-3-52

This article is available from: http://www.rbej.com/content/3/I/52

(c) 2005 Talbot and Riveles; licensee BioMed Central Ltd.

This is an Open Access article distributed under the terms of the Creative Commons Attribution License (http://creativecommons.org/licenses/by/2.0), which permits unrestricted use, distribution, and reproduction in any medium, provided the original work is properly cited.
Received: 02 August 2005

Accepted: 28 September 2005

\begin{abstract}
The oviduct is an exquisitely designed organ that functions in picking-up ovulated oocytes, transporting gametes in opposite directions to the site of fertilization, providing a suitable environment for fertilization and early development, and transporting preimplantation embryos to the uterus. A variety of biological processes can be studied in oviducts making them an excellent model for toxicological studies. This review considers the role of the oviduct in oocyte pick-up and embryo transport and the evidence that chemicals in both mainstream and sidestream cigarette smoke impair these oviductal functions. Epidemiological data have repeatedly shown that women who smoke are at increased risk for a variety of reproductive problems, including ectopic pregnancy, delay to conception, and infertility. In vivo and in vitro studies indicate the oviduct is targeted by smoke components in a manner that could explain some of the epidemiological data. Comparisons between the toxicity of smoke from different types of cigarettes, including harm reduction cigarettes, are discussed, and the chemicals in smoke that impair oviductal functioning are reviewed.
\end{abstract}

\section{A. Background}

Exposure to cigarette smoke may be either active or passive, and the type of smoke inhaled in each case has a different origin. Mainstream smoke is the smoke that an active smoker inhales with each puff, while sidestream smoke, the main component of environmental tobacco smoke, burns off the end of a lit cigarette and is the smoke inhaled by passive smokers. While the association between inhalation of mainstream smoke and cardiovascular disease and cancer has been established for many years, the impact of smoking on reproduction is recognized, but less well characterized and less well known [1]. Epidemiological studies have repeatedly shown that women of child bearing age who actively inhale mainstream smoke have higher rates of infertility, spontaneous abortion, ectopic pregnancy, tubal infertility, increased time to conception, and intrauterine growth retardation than nonsmokers [2-15]. Increases in infertility and ectopic pregnancy in smokers could be due to impairment of oviductal functioning. In patients with primary tubal infertility, 39\% were smokers when they started trying to conceive in contrast to only $16 \%$ in the non-smoking group $(\mathrm{OR}=2.7)[10]$. Heavy smoking (> 5 pack-years $)$ increased the odds ratio to 4.2 , and similar dose related effects have been repeatedly observed $[11,16]$.

The realization that sidestream smoke exposure adversely affects human health is even more recent [17]. In 1992, the Environmental Protection Agency published a monograph summarizing evidence that exposure to 
environmental tobacco smoke can produce adverse effects on cardiovascular and lung health and encouraged broader investigation in this area [17]. Subsequently, a number of studies have addressed the effect of passive smoking on various aspects of human health including reproduction and have concluded that adverse reproductive outcomes, such as delayed time to conception and reduced birth weight, do occur as a consequence of exposure to environmental tobacco smoke during pregnancy [18-30]. Moreover, an in vitro fertilization lab recently concluded that while fertilization rates and embryo quality were similar in smokers and non-smokers, implantation and pregnancy rates were adversely affected by both active and passive smoking when compared to non-smoking controls [31].

Recent reviews have addressed issues of cigarette smoke exposure and various facets of reproduction including delayed time to conception, ovarian effects and premature menopause, implantation failure, fetal growth restriction and growth retardation, placental abnormalities, reduced fecundity, congenital abnormalities, and effects on male reproduction [32-34]. However, most prior reviews have not considered smoke's interaction with the oviduct, an organ vital to reproduction. The purpose of this paper is to review the functions of the oviduct, in particular those that involve movement of gametes and embryos, and to evaluate evidence that exposure to mainstream or sidestream cigarette smoke can negatively impact oviductal functioning and thereby adversely affect reproductive outcomes. We will also consider evidence that commercial cigarettes, including harm reduction and light cigarettes, contain toxicants that impair oviductal functioning, and we will discuss the specific chemicals in smoke that impair oviductal functioning. Some of these chemicals adversely affect oviductal processes at extremely low doses, are often considered safe, and are added to cigarettes and other consumer items.

\section{B. Functions of the oviduct}

The oviduct, which is divided anatomically into the infundibulum, ampulla, and isthmus, plays important roles in mammalian reproduction (Fig. 1) [35-41]. The infundibulum is responsible for picking-up the oocyte cumulus complex following ovulation and moving it into the ampulla where fertilization occurs. Simultaneously, the oviduct moves sperm in the opposite direction from a reservoir near the uterotubal junction toward the ampulla [42]. The oviduct also provides a suitable microenvironment for capacitation of spermatozoa, fertilization, preimplantation development, and transport of the preimplantation embryos to the uterus. The movement of the embryo through the oviduct to the uterus is carefully timed by ovarian hormones and signals from the embryos [43]. While smoke exposure could affect any of these

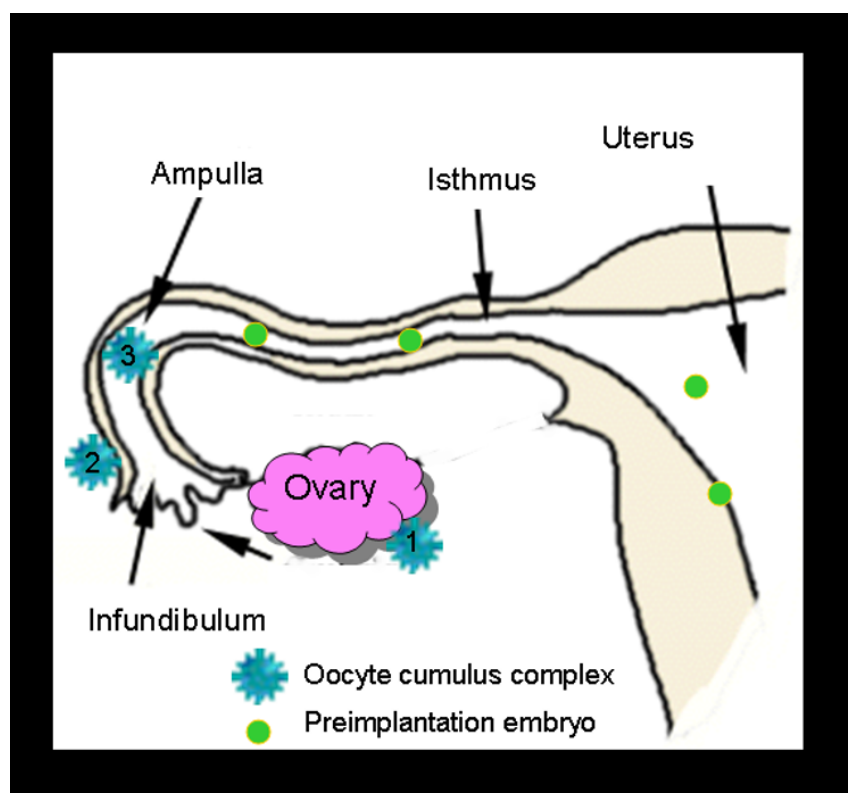

\section{Figure I}

Schematic diagram showing the three anatomical regions of the oviduct (infundibulum, ampulla, and isthmus) and the regions of the oviduct where oocyte cumulus complexes and preimplantation embryos can be found. Oocyte cumulus complexes are ovulated from ovaries (\#I), picked-up by the outer surface of the infundibulum (\#2), and moved toward the ostium (unlabeled arrow) by ciliary beating then into the ampulla for fertilization (\#3). Fertilized eggs and embryos are transported through the isthmus to the uterine cavity where they then can implant in the uterine wall.

processes, most current evidence links smoke to effects on oocyte cumulus complex pick-up and embryo transport, which will be reviewed in more detail in the following sections.

(I) Oocyte cumulus complex pick-up by the infundibulum The infundibulum is the portion of the oviduct closest to the ovary and is responsible for picking up the oocyte cumulus complex following its ovulation from a mature ovarian follicle $[44,45]$. The oocyte cumulus complex consists of a centrally located oocyte, which is in turn surrounded by the zona pellucida, corona radiata, and cumulus cells (Fig. 2) [46-48]. The complex contains 5,0008,000 cumulus cells, depending on the species, and these are separated from each other by an extracellular matrix, which plays an important role in the pick-up process. The structure and distribution of the extracellular matrix between cumulus cells has been well characterized in a number of species including humans [46,49-52]. Biochemically, the matrix is rich in hyaluronan (hyaluronic acid) [53-55], which is cross-linked by inter-alpha trypsin 


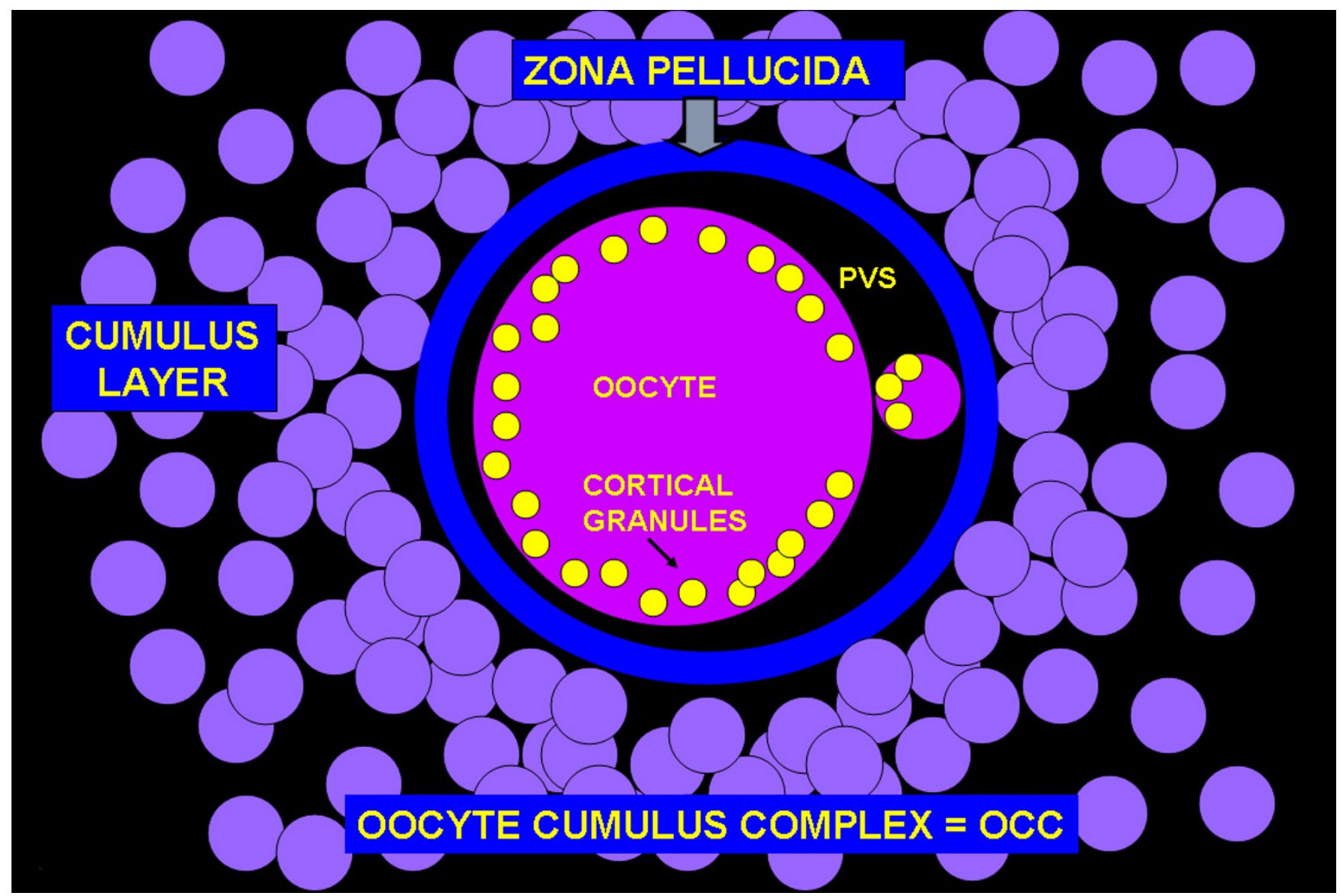

\section{Figure 2}

Schematic diagram of an oocyte cumulus complex after ovulation from an ovarian follicle. The oocyte and polar body are contained within the zona pellucida. Immediately outside the zona, cells are densely packed to form the corona radiata outside of which are numerous cumulus cells. The cumulus cells are widely separated from each other by spaces filled with an extracellular matrix (matrix is shown in Figure 5).

inhibitor [56-58]. TSG-6 (the secreted product of the tumor necrosis factor-stimulated gene 6) also binds to hyaluronan in the cumulus matrix [59-61]. The importance of these matrix components to reproduction is demonstrated by the TSG-6 knockout mouse which fails to assemble a cumulus matrix and is infertile [62].

Oocyte pickup by the infundibulum is a complex process that involves both ciliary beating and adhesion between the oviductal epithelium and the oocyte cumulus complex [63-73]. Both the inner and outer surfaces of the infundibulum are covered with ciliated epithelium (Fig. 3) [74]. Following ovulation, the oocyte cumulus complex travels along the outer surface of the infundibulum and enters the oviduct through the ostium (Fig. 3) $[45,75]$. The complex then rapidly moves to the ampulla where fertilization occurs. Although infundibular smooth muscle may contract during the pick-up process, it does not appear to be necessary for pick-up, which still occurs when muscle contraction is inhibited with isoproterenol [76].

Huang et al., developed an in vitro method for measuring oocyte pickup rate using hamster infundibula [71]. At room temperature, oocyte pickup rate averaged $55.2+$ $10.6 \mathrm{um} / \mathrm{sec}$ and was dependent on the viscosity of the culture medium and temperature. Moreover, complexes were observed to move along particular pathways on the surface of the infundibula depending on where they were placed. This in vitro bioassay has subsequently evolved to allow measurement of smooth muscle contraction [77] and adhesion of the oocyte cumulus complex to the infundibulum [72]. 


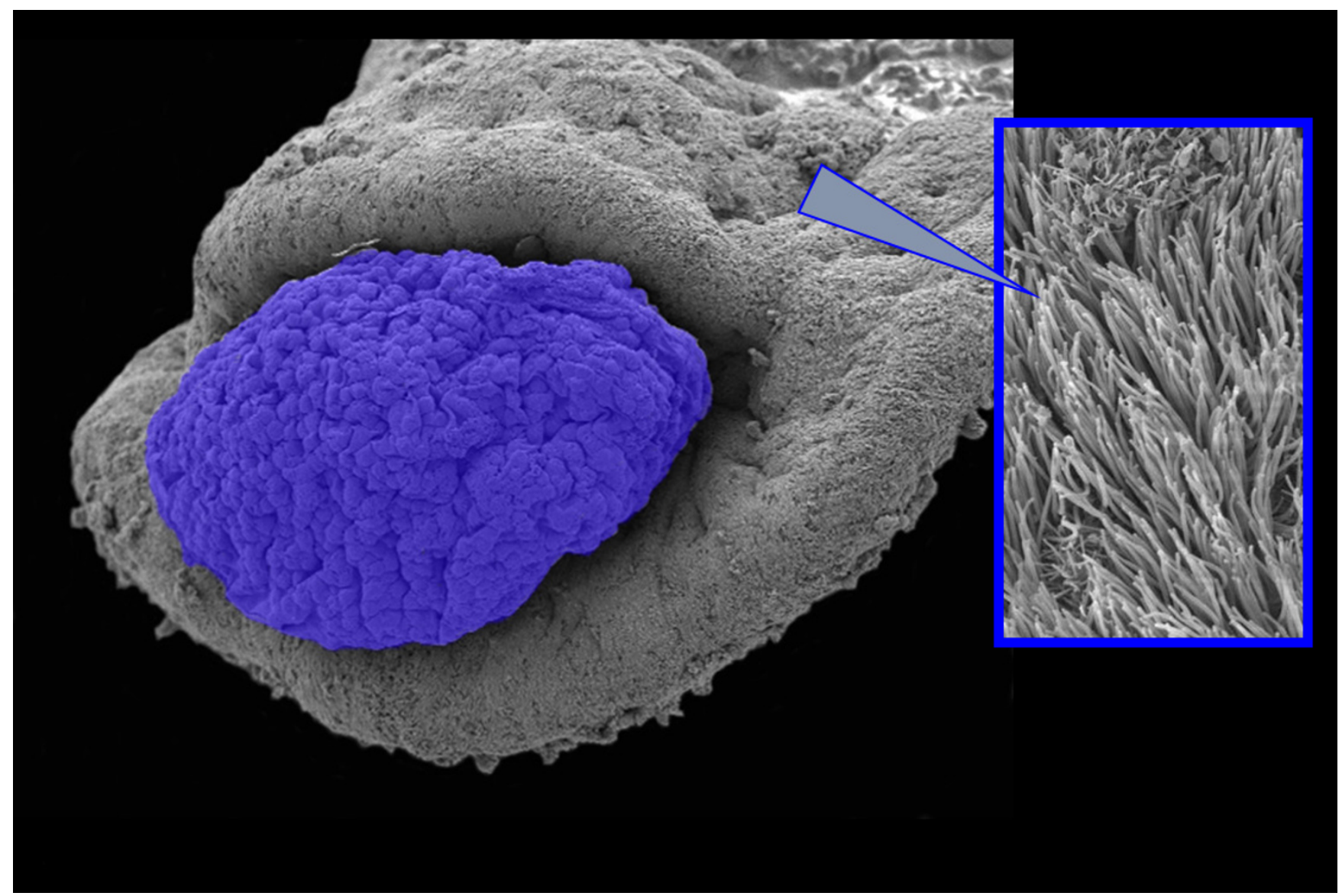

Figure 3

Scanning electron micrograph showing a hamster oocyte cumulus complex, colorized blue, entering the ostium of an infundibulum. The outer and inner surfaces of the infundibulum are covered with cilia (inset).

The hamster infundibular explant has also been used to analyze the process of pick-up in hamsters in conjunction with video microscopy [45]. While small particles such as Lycopodium spores can move over the infundibular surface in the currents created by ciliary beating [45,78], the large mass of the oocyte cumulus complex does not allow it to move in the fluid currents created by ciliary beating alone. In addition to ciliary beating, adhesion between the cumulus cell matrix and the tips of the cilia is necessary to move the complex over the surface of the infundibulum $[45,72]$. The cumulus matrix attaches the complex to the infundibulum, and as the cilia beat in the direction of the ostium, the oocyte cumulus complex glides over the surface of the infundibulum until it reaches and enters the ostium. Figure 4 (Additional file 1) links to a video showing the movement of a hamster oocyte cumulus complex over the surface of an infundibulum. Additional videos of this process can be viewed at http://www.talbotcen tral.ucr.edu/oocytemovie.htm. In hamsters, the oocyte cumulus complex is larger in diameter than the opening of the ostium, and in order for the complex to enter the oviduct, it goes through a "churning" process that compacts the matrix between the cumulus cells making the complex small enough to pass through the ostium [45]. During churning, the oocyte is sometimes squeezed from the center of the complex to the periphery. Pick-up of a human oocyte cumulus complex has been observed in vivo using transvaginal hydrolaparascopy and involves adhesion of the complex to the tumescent fimbria of the infundibulum with ciliary beating drawing the complex into the ostium [75].

Adhesion plays an essential role in the pick-up process (Fig. 5) $[66,72]$. Oocytes denuded of cumulus cells are not picked up [66], and when matrix is not secreted by the cumulus cells, the complex fails to attach to the infundibulum and it is not moved into the oviduct [72]. Polycationic compounds can block oocyte cumulus 


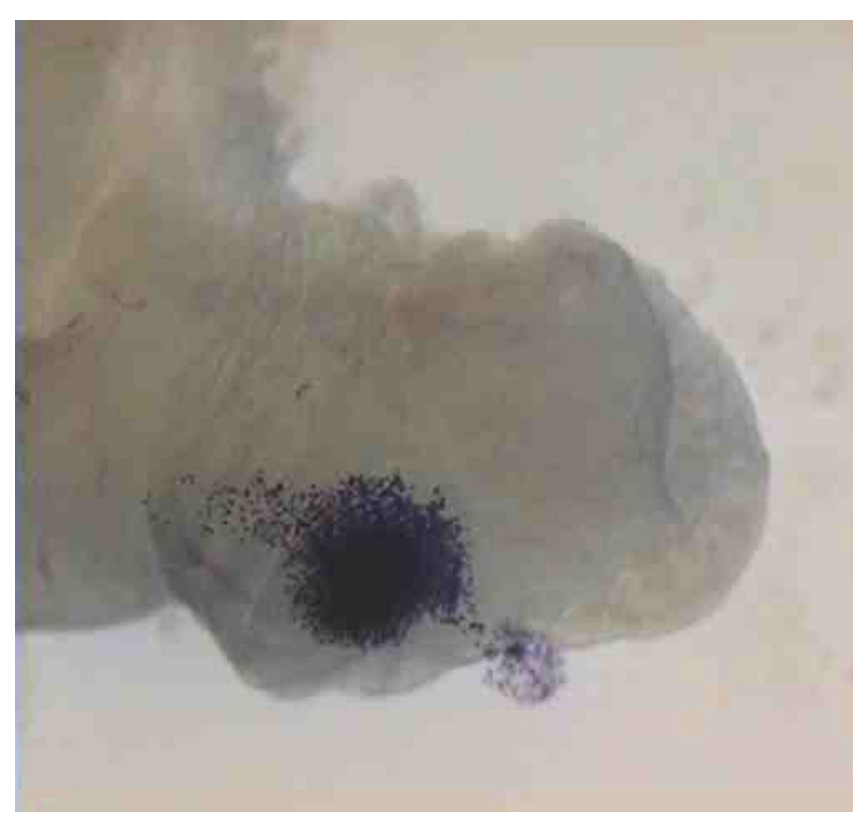

\section{Figure 4}

Micrograph showing a hamster oocyte cumulus complex, stained blue, on the outer surface of an infundibulum. Click the link to view a video of this complex being picked up by the oviduct. Reprinted from Molec Biol Cell 10:5-9, 1999 (with permission). See also http://www.rbej.com/imedia/ 2132055580757722/supl.mov

complex pick-up apparently by blocking transient adhesion between the tips of the cilia and the complex [67]. Interestingly, peritoneal fluid from women with endometriosis contains a macromolecule $(<100,000 \mathrm{kDa})$ that when assayed with hamster infundibula in vitro coats the cilia on the surface of the infundibula and blocks adhesion and hence pick-up of the human oocyte cumulus complex by the hamster infundibulum $[79,80]$. Transmission electron microscopy revealed that adhesion during complex pickup occurs specifically between the cumulus matrix and the crowns at the tips of the infundibular cilia [72]. An in vitro assay using vacuum from a low flow peristaltic pump has been developed to measure adhesion between the oocyte cumulus complex and infundibulum [72]. This assay was used to show that factors that either increase or decrease adhesion can interfere with the pickup process. If the matrix of the oocyte cumulus complex is made less sticky by compacting it or treating it with polyl-lysine, the complex cannot adhere tightly enough to the infundibulum to be successfully picked up [72]. Conversely, if adhesion is increased, for example by treating complexes or the oviduct with the lectin wheat germ agglutinin, ciliary beating is not strong enough to transiently detach the complex and move it to the ostium.
Thus successful pick-up requires a delicate balance between proper strength of adhesion of the complex to the infundibulum and ciliary beating towards the ostium.

The ampulla serves as a reservoir for the oocyte cumulus complex, and hormonally controlled oviductal secretions play an important role in creating a suitable microenvironment for fertilization and initial preimplantation development $[37,44,81,82]$. After entering the female reproductive tract, sperm are stored in a reservoir near the uterotubal junction [42]. As some sperm leave the reservoir and move through the isthmus of the oviduct, they become fully capacitated and their motility becomes hyperactivated $[38,83,84]$. Hyperactivation is thought to be critical to fertilization as it allows sperm to detach from the oviductal epithelium, move in the lumen of the oviduct, and penetrate through the extracellular matrices surrounding the oocyte [84]. Sperm meet the oocyte cumulus complex in the ampulla where fertilization normally occurs, and after fertilization, the preimplantation embryo undergoes cleavage as it is transported through the ampulla and the isthmus to the uterus for implantation [47]. Movement through the ampulla may involve both ciliary beating and smooth muscle contraction. When sections of the ampulla were surgically reversed in their orientation, few rabbits became pregnant [85]. In cases where pregnancy did occur, muscle contraction apparently overcame ciliary beating toward the ovary, showing that the cilia in the ampulla normally play an important role in controlling movement into the isthmus [85]. The isthmus of the oviduct is essential for normal reproduction, as its removal results in infertility [86].

\section{(2) Transport of preimplantation embryos to the uterus}

A number of factors can influence the transport of preimplantation embryos through the ampulla and isthmus of the oviduct. Interestingly, the oviduct can distinguish between unfertilized oocytes and preimplantation embryos. which are transported at different rates, with embryos reaching the uterus one day earlier than unfertilized oocytes [87]. The production by embryos of plateletactivating factor (PAF), which mediates signaling to the oviduct, accelerates the passage of preimplantation embryos, but not oocytes, through the oviduct [88]. PAF may affect transport by increasing ciliary beating [89]. Human embryos likewise release PAF in vitro, and human oviducts synthesize both the PAF receptor and PAF acetylhydrolase, which degrades PAF, further supporting a role for PAF in the embryo-oviductal dialogue [90]. When rat embryos of different ages were transferred to the oviduct of pregnant females, older embryos reached the uterus before younger ones, again suggesting differential transport rates of embryos that depend on age [91]. These data from hamsters and rats support the idea that embryo transport is at least, in part, subtly controlled by the 

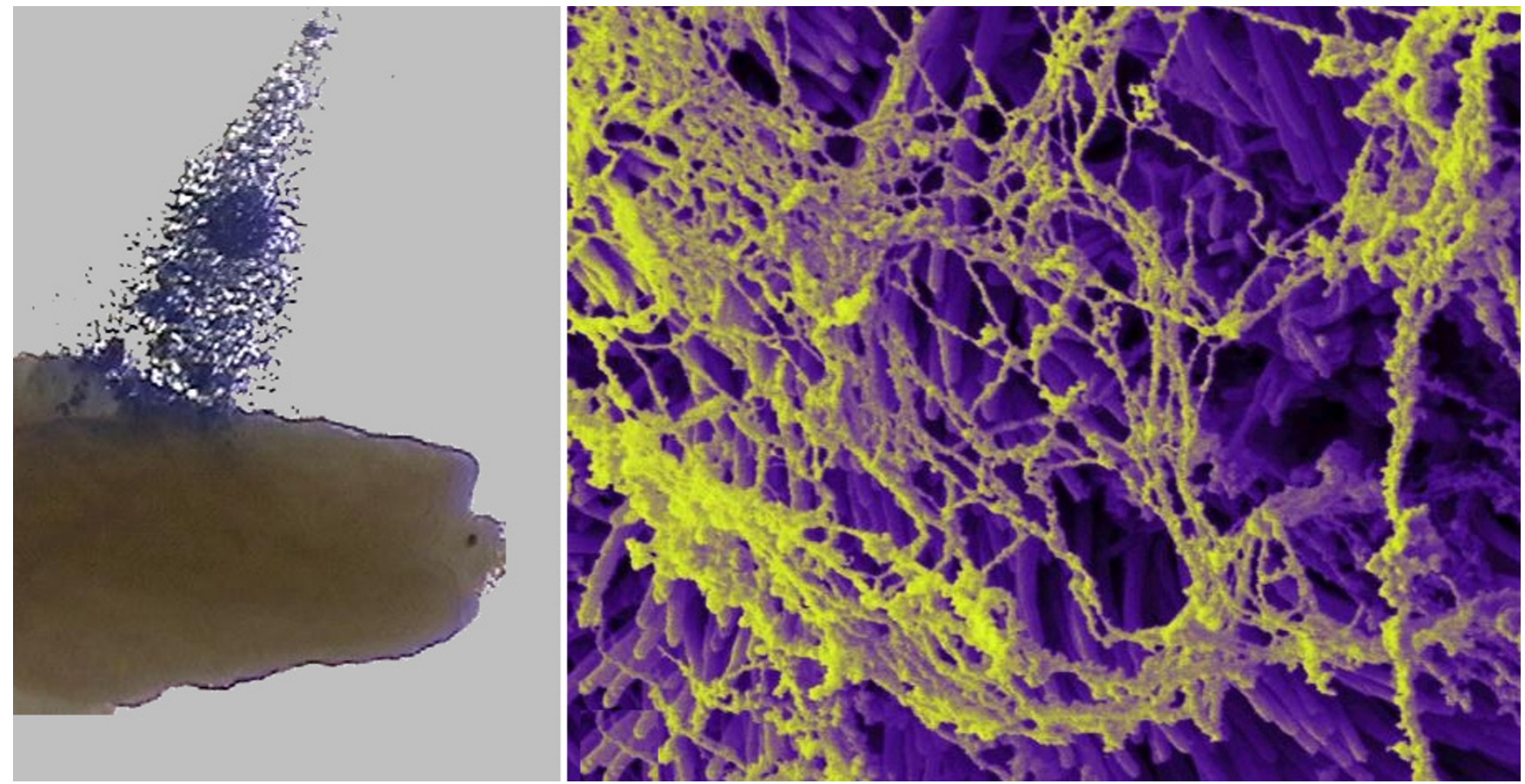

\section{Figure 5}

Micrographs showing adhesion between the oocyte cumulus complex and the infundibulum. (A) Stereoscopic micrograph of an oocyte cumulus complex, colorized blue, being pulled off the surface of an infundibulum using forceps. The matrix of the complex adheres to the infundibulum. Complexes do not adhere to most other surfaces. (B) Scanning electron micrograph of cumulus matrix adhering to cilia on the outer surface of an infundibulum. The matrix was left behind by an oocyte cumulus complex that was picked-up by the infundibulum.

embryos themselves. Other factors such as maternal age and parity also influence embryo transport [92]. In hamsters, transport to the uterus occurred faster in young nulliparous females than in nulliparous or multiparous adult females. In the group of young females, but not the adults, development of the embryos was also highly synchronous.

Transport of preimplantation embryos through the oviduct is accomplished by smooth muscle contraction and ciliary beating $[76,93]$. However, the relative contributions of these two processes are not yet completely understood, and it is probable that both play roles in transport. The ampulla and isthmus are both lined by ciliated cells, which beat in the direction of the uterus [76]. The relative number of cilia decreases and the thickness of the muscle layers increases proceeding toward the uterine end [94], suggesting that cilia become relatively less important in the isthmus. Muscle contraction produces oscillating movements in the isthmus $[64,95,96]$ that result in a net transport of preimplantation embryos towards the uterus [97]. Nitric oxide synthase inhibitors increased muscular activity in rats, and this was accompanied by increased rate of movement of eggs or microspheres in the oviduct [97]. These data support the idea that that muscle contraction can modulate (speed or slow) transport through the oviduct. Muscle contractions may also be important in keeping embryos grouped together as they are transported through the isthmus [98].

Muscle contraction in the oviduct is regulated by a variety of factors; however, the interplay of these factors with each other is not yet well understood. The oviductal muscles are innervated by the sympathetic nervous system $[99,100]$. Stimulation of $\alpha$ adrenergic receptors promotes contraction of the oviductal muscles, while stimulation of $\beta$ receptors inhibits contractions [100-102]. Alternating contraction and relaxation produce the oscillatory movements involved in embryo transport. However, the adrenergic neurons may not be the primary means for controlling embryo transport since experimental depletion or inhibition these neurons does not prevent transport nor decrease fertility [35]. Chemicals produced by the oviduct itself or the preimplantation embryo can also modulate muscle contraction and may play the lead role 
in embryo transport. Oviductal muscle responds to sex steroids and prostaglandins. Endogenous estrogens stimulate oviductal muscle contraction, while progesterone relaxes it [103]. Likewise the prostaglandins PGF and PGE contract and relax oviductal muscle respectively [104106]. Human oviduct smooth muscle also produces the prostaglandin prostacyclin which decreases muscle contractility and may affect embryo transport [107]. Oviductal smooth muscle also contains a nitric oxide system [108] that promotes muscle relaxation [109]. Inhibition of nitric oxide syntheses in rats increases oviductal motility and results in accelerated movement of embryos through the oviduct [97]. In additions to prostaglandins, the oviduct produces, endothelin-1 [110] and angiotensin II [111] which are involved in modulating oviductal muscle contraction and regulation of embryo transport. Recent data from the cow suggest that tumor necrosis factora from the oviductal epithelium, immune cells of the oviduct, or even the embryo itself stimulates the release of these effectors from the oviductal epithelial cells [111]. A newly uncovered transport regulatory mechanism involves the cannabinoid receptor CB1 [112]. When CB1 is genetically or pharmacologically silenced, embryos are retained in the oviduct. This effect can be reversed by isoproterenol, a $\beta$ adrenergic agonist. These data suggest that cannabinoid signaling is important in coordinating oviductal muscle contraction, and is necessary for proper embryo transport. While this review deals with conventional cigarette exposure, these results with the CB1 receptor suggest that exposure to marijuana for either recreational use or pain relief could affect embryo transport and hence female fertility. It is clear from the preceding that the regulation of embryo transport through the oviduct is complex and may depend on multiple regulatory mechanisms, some of which are just now being identified.

\section{(3) Biological importance of pick-up and transport by the oviduct}

Timing of oocyte pick-up and embryo transport is critical as the preimplantation embryos must arrive in the uterus during the window when implantation can occur $[113,114]$. If the oocyte is not picked up by the oviduct or if the embryo moves through the oviduct too quickly or too slowly, implantation may fail to occur or may be ectopic. In rats, embryo transport was accelerated by treatment with methoxychlor, an estrogenic pesticide, and the embryos failed to implant in the uterus [115]. Likewise women treated with ergonovine maleate, a powerful stimulant of oviductal contraction, showed decreased conception rates when the drug was delivered immediately post coitus [116]. Interference with embryo transport can adversely affect fertility and in humans lead to ectopic implantation.

\section{Evidence that the oviduct is a target of cigarette smoke}

While epidemiological studies have been clear in identifying increased reproductive risks for women who smoke both actively and passively (Section A), the reasons that smoke causes reproductive problems are usually not understood. Some of the risk factors for women smokers, such as ectopic pregnancy, failure to conceive, increased time to conception, could be due to effects of smoke on the pick-up and transport by the oviduct. We will next examine the in vivo and in vitro evidence supporting the idea that the oviduct is targeted by cigarette smoke.

\section{(I) In vivo evidence that the oviduct is a target of smoke}

Direct inhalation of whole smoke has been shown in several studies to adversely affect the oviduct. Oviductal motility is altered in humans [117] and in rabbits [118] by inhalation of mainstream smoke. Inhalation of mainstream or sidestream smoke by hamsters, at serum cotinine levels that were within the ranges found in active and passive human smokers (mainstream $=72.8$ and sidestream $=14.9 \mathrm{ng}$ cotinine $/ \mathrm{mL}$ ) produced blebbing of the oviductal epithelium at the ultrastructural level and decreased the ratio of ciliated to secretory cells in the ampulla [119]. In a related study on hamsters, inhalation of either mainstream or sidestream smoke at levels that produced serum cotinine levels equivalent to those in human smokers (mainstream $=50-250$ and sidestream $=$ 18-80 ng cotinine/ml) slowed preimplantation embryo transport through the oviduct [120]. In addition, muscle contractions of the ampulla were significantly inhibited in vivo during smoke exposure, supporting the conclusion that embryo transport rates were slowed by inhibition of smooth muscle contraction [120]. While smooth muscle contraction rates did increase after smoke exposure stopped, they did not return to control levels, showing that inhibition of contraction by smoke is not immediately completely reversible.

Several in vivo studies using animal models have established that the oviduct is a target of nicotine, a major constituent of cigarette smoke. When administered to mice in drinking water, nicotine $(108 \mu \mathrm{mol} / \mathrm{L})$ significantly decreased $\mathrm{Na}$ and $\mathrm{K}$ ion concentrations in the oviductal epithelium [121]. In addition, nicotine injected subcutanenously ( $2.5 \mathrm{mg}$ twice daily) into rats produced a significant increase in lactate dehydrogenase levels in flushings of the oviduct in early pregnancy [122]. While a change in the ionic composition of the oviductal epithelium or its secretions might adversely affect adhesion of the oocyte to the oviductal surface and the oocyte pick-up process, the relationship between these nicotine-induced changes and oviductal functioning has not yet been established experimentally. Nevertheless, these studies do 
demonstrate that nicotine exerts effects on the oviductal epithelium.

Two additional studies on rats indicate further effects of nicotine on oviductal functioning. When pregnant rats were treated with pharmacological doses of nicotine (2.5 mg injected subcutaneously twice daily), preimplantation embryo transport was inhibited [123]. In addition, nicotine $(5 \mathrm{mg} / \mathrm{kg})$, when injected subcutaneously twice daily in pregnant rats, both retarded embryonic development and reduced blood flow to the oviduct [124]. Reduction of oviductal blood flow decreases smooth muscle contraction, which in turn can delay embryo transport $[124,125]$. In other studies, nicotine slowed oviductal contraction in vivo in the Rhesus monkey, which may prevent implantation [126]. Oral nicotine administration through drinking water $(108 \mu \mathrm{mol} / \mathrm{L})$ also interfered with oocyte maturation, fertilization, and early pregnancy in mice [121]. Collectively these data show that nicotine affects the composition and secretions of the oviductal epithelium, adversely affects preimplantation development, retards movement of embryos through the oviduct, and reduces blood flow to this organ.

In a study involving gamete intrafallopian transfer (GIFT), no differences were found among active, passive and nonsmokers in number of oocytes retrieved; however the number of live births after GIFT was significantly lower for active smokers $(10.5 \%)$ than for passive smokers $(23.1 \%)$ or non-smokers (33.3\%) smokers [127], which could indicate an effect of smoke on the human oviduct.

Taken together these in vivo studies demonstrate that the oviduct responds to exposure to both whole mainstream and sidestream smoke and to nicotine and that the transport of preimplantation embryos can be inhibited by cigarette smoking, apparently by an inhibition of oviductal smooth muscle contraction. In vivo studies have not yet been undertaken to determine if oocyte cumulus complex pick-up is slowed in smoke exposed animal models or humans.

\section{(2) In vitro evidence that smoke affects oviductal functioning}

In vitro models have facilitated studies on smoke's effect on the oviduct and have further supported the conclusion that the oviduct is responsive to chemicals in cigarette smoke (Fig. 6, additional file 2). A hamster infundibular explant model [71] has been used to simultaneously measure ciliary beat frequency, adhesion, oocyte pick-up rate, and muscle contraction, before, during, and after exposure to smoke or its constituents [70,128-133]. In general, in vitro studies show that mainstream and sidestream smoke solutions adversely affect proper functioning of the oviduct. Mainstream and sidestream smoke solutions made from University of Kentucky 2R1 research cigarettes in a medium lacking bovine serum albumin (BSA) inhibited ciliary beat frequency in a dose dependent manner [128]. When BSA was included in the medium, mainstream solutions continued to inhibit beat frequency, while sidestream solutions either had no effect or slightly stimulated beat frequency, suggesting that the presence of BSA influenced how sidestream smoke affected beat frequency [129]. Interestingly, in both mainstream and sidestream solutions containing BSA, oocyte pickup rate was inhibited in a dose-dependent manner with sidestream smoke often being more inhibitory than mainstream smoke (Fig. 6). Since ciliary beat frequency was either not affected or slightly stimulated in sidestream smoke, these data show that smoke can inhibit oocyte pick-up rate by affecting factor(s) other than ciliary beat frequency. Oocyte pickup rate was more sensitive to the gas than the particulate phase of mainstream and sidestream smoke solutions [129].

Since pick-up rate decreased in sidestream smoke when beat frequency increased, oocyte pick-up rate must depend on factor(s) other than ciliary beat frequency [129]. Since adhesion of the oocyte cumulus complex to the tips of the cilia is important in oocyte pick-up $[66,68,72]$, the effect of smoke solutions on adhesion was measured in vitro using the hamster infundibular model. Both mainstream and sidestream solutions inhibited oocyte cumulus complex pick-up rate and increased adhesion of the cumulus to the oviduct [133]. As was shown previously using wheat germ agglutinin [72], increasing adhesion by exposure to smoke leads to a decrease in pick-up rate since the complex can not be moved by the cilia if it adheres too tightly to the oviduct. These effects on adhesion and pick-up rate were observed when only the oocyte cumulus complex was pretreated with smoke solution or when only the infundibulum was pretreated, indicating that both the cumulus matrix and oviduct are targets of smoke treatment [133]. The oviduct was more sensitive to treatment than the oocyte cumulus complex, perhaps because smoke pretreatment affected both ciliary beat frequency and adhesion of infundibula but only adhesion of oocyte cumulus complexes. These data indicate that factors that increase adhesion of the oocyte cumulus complex to the cilia can decrease pick-up rate and explain why both mainstream and sidestream smoke solutions decrease pick-up rate even when ciliary beat frequency is increased by treatment with sidestream smoke.

The above studies were all done using non-filtered 2R1 research brand cigarettes manufactured at the University of Kentucky. A subsequent study examined the effects on oviductal functioning of smoke solutions from a filtered research brand cigarette $(1 \mathrm{R} 4 \mathrm{~F})$, various traditional 

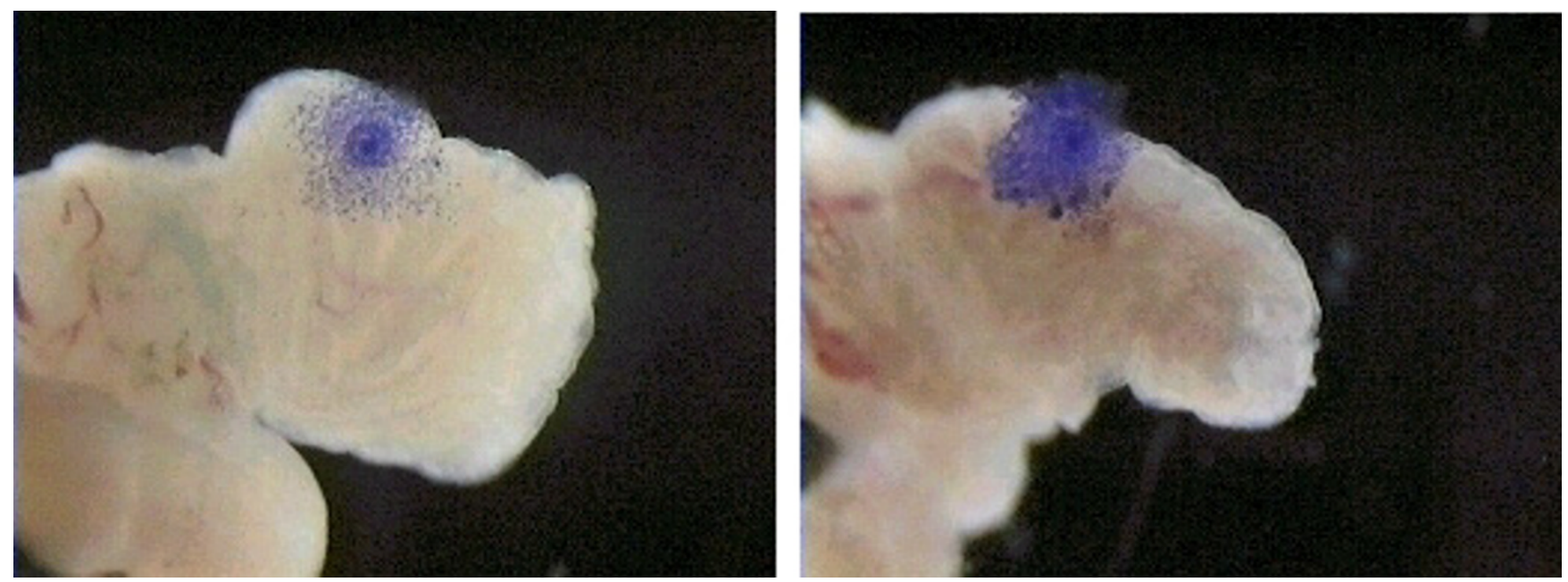

\section{Figure 6}

Micrographs showing oocyte cumulus complex pick-up by a hamster infundibulum of a control (6B) and a sidestream smoke treated (6A) preparation. Click the link to view a video of this experiment. During approximately 10 seconds of observation, the control complex moves toward the ostium while the smoked treated complex does not move. Reprinted from Molec Biol Cell 10:5-9, 1999 (with permission). See also http://www.rbej.com/imedia//6226|4392757722/sup2.mov

filtered and non-filtered commercial cigarettes (Marlboro Red, Marlboro Light, Camel filtered, Camel unfiltered, Kool, and Kool with the filter removed), and three brands of harm reduction cigarettes (Advance, Omni and Omni Light) [134]. Harm reduction cigarettes have recently been introduced commercially and are claimed to contain fewer carcinogens than traditional commercial brands [135]. All of the cigarettes tested (research, traditional commercial, harm reduction) adversely affected oviductal functioning, and the effects were in general stronger on oocyte pick-up rate and smooth muscle contraction than on ciliary beating. Sidestream smoke generally produced a stronger effect in all assays than mainstream smoke solution. Smoke from the 1R4F cigarettes, which more closely resemble the commercial brands smoked today than the 2R1 cigarettes, was considerably more inhibitory in the pick-up rate and muscle contraction assays than the $2 \mathrm{R} 1 \mathrm{~s}$. Except for mainstream smoke from Marlboro Lights and Kools, all traditional brand smoke solutions reduced pickup rate by more than $60 \%$. Except for mainstream smoke from Marlboro Lights and Camel filtered, all smoke solutions from traditional brands reduced muscle contraction by more than $80 \%$. Smoke from harm reduction cigarettes reduced pick-up rate by $50-80 \%$ and reduced muscle contraction by $30-98 \%$ depending on the type of smoke and brand. These data show that the adverse effects observed on oviducts with 2R1 research cigarettes are also produced by filtered research cigarettes and by filtered, non-filtered and light commercial brands. Moreover, harm reduction cigarettes, while reduced in levels of carcinogens, still contain toxicants that can impair oviductal functioning.

Pick-up rate could also be altered by action of smoke on the oocyte cumulus complex, in particular the matrix which is required for adhesion to the cilia [72]. Both mainstream and sidestream smoke solutions from 2R1 cigarettes caused more dispersal of hamster cumulus cells during in vitro incubation than control medium lacking smoke, and oocyte pick-up rate was slowed when oocyte cumulus complexes were pretreated with smoke prior to measuring pick-up rate [133]. In addition, in vitro exposure of porcine oocyte cumulus complexes to nicotine, cadmium, and anabasine, all components of cigarette smoke, suppressed FSH induced expansion of the cumulus and decreased synthesis and accumulation of hyaluronic acid in the cumulus matrix [136]. These studies show that the matrix of the oocyte cumulus complex is also a target of cigarette smoke and damage to the matrix can affect pick-up of complexes by the oviduct.

\section{What chemicals in cigarette smoke impair oviductal functioning? \\ (I) Chemicals most studied in smoke}

Cigarette smoke is a complex suspension that contains over 4,000 chemicals distributed between a gaseous and particulate phase [17]. Most studies on cigarette smoke and its components have focused on nicotine [137-139], carcinogens [140,141], polycyclic aromatic hydrocarbons (PAHs) [142-144], such as benzo-a-pyrene, tobacco-spe- 
Table I: Chemicals in Cigarette Smoke that Impair Oviductal Functioning '

\begin{tabular}{|c|c|c|c|c|c|c|}
\hline \multicolumn{7}{|c|}{ LOAELs $(M)^{2}$} \\
\hline CHEMICALS & Oocyte & Ciliary Beat & Contraction & FEMA & FDA & ADDED $^{5}$ \\
\hline & Pick-up Rate & Frequency & Rate & GRAS $^{3}$ & EAFUS 4 & \\
\hline \multicolumn{7}{|l|}{ PYRIDINES } \\
\hline 2-ethylpyridine & $9.35 \times 10^{-12}$ & $9.35 \times 10^{-12}$ & $9.35 \times 10^{-12}$ & & & \\
\hline 4-methylpyridine & $9.50 \times 10^{-11}$ & $9.50 \times 10^{-11}$ & $9.50 \times 10^{-11}$ & & & \\
\hline 2-methylpyridine & $9.35 \times 10^{-11}$ & $9.35 \times 10^{-11}$ & $9.35 \times 10^{-10}$ & & & \\
\hline 4-ethenylpyridine & $9.30 \times 10^{-11}$ & $9.30 \times 10^{-9}$ & $9.30 \times 10^{-11}$ & & & \\
\hline 3-ethylpyridine & $9.33 \times 10^{-10}$ & $9.33 \times 10^{-11}$ & $9.33 \times 10^{-10}$ & $\sqrt{ }$ & $\sqrt{ }$ & $\sqrt{ }$ \\
\hline Nornicotine & $6.85 \times 10^{-9}$ & $6.85 \times 10^{-8}$ & $6.85 \times 10^{-8}$ & & & \\
\hline beta-nicotyrine & $6.33 \times 10^{-9}$ & $6.30 \times 10^{-8}$ & $x^{6}$ & & & \\
\hline 2,4,6-trimethylpyridine & $8.25 \times 10^{-8}$ & $8.25 \times 10^{-6}$ & $8.25 \times 10^{-8}$ & & & \\
\hline 2,4-dimethylpyridine & $9.34 \times 10^{-7}$ & $x^{6}$ & $9.34 \times 10^{-9}$ & & & \\
\hline 2,3-dimethylpyridine & $9.34 \times 10^{-7}$ & $9.34 \times 10^{-7}$ & $x^{6}$ & & & \\
\hline 4,4-bipyridine & $8.78 \times 10^{-6}$ & $8.78 \times 10^{-7}$ & $8.78 \times 10^{-4}$ & & & \\
\hline 2,5-dimethylpyridine & $9.34 \times 10^{-5}$ & $x^{6}$ & $9.34 \times 10^{-5}$ & & & \\
\hline 3,4-dimethylpyridine & $1.76 \times 10^{-5}$ & $x^{6}$ & $1.76 \times 10^{-4}$ & & & \\
\hline pyridine & $1.27 \times 10^{-5}$ & $1.27 \times 10^{-3}$ & $1.27 \times 10^{-3}$ & $\sqrt{ }$ & $\sqrt{ }$ & $\sqrt{ }$ \\
\hline 3-methylpyridine & $1.23 \times 10^{-5}$ & $X^{d}$ & $1.23 \times 10^{-2}$ & & & \\
\hline 2,2-bipyridine & $8.74 \times 10^{-4}$ & $8.74 \times 10^{-2}$ & $8.74 \times 10^{-2}$ & & & \\
\hline cotinine & $2.84 \times 10^{-2}$ & $2.84 \times 10^{-5}$ & $x^{6}$ & & & \\
\hline nicotine & $9.01 \times 10^{-2}$ & $x^{6}$ & $6.70 \times 10^{-2}$ & & & \\
\hline \multicolumn{7}{|l|}{ PYRAZINES } \\
\hline 2-methoxy-3-methylpyrazine & $10^{-12}$ & $10-9$ & $10^{-12}$ & & & \\
\hline pyrazine & $10^{-11}$ & $10^{-12}$ & $10^{-9}$ & $\sqrt{ }$ & $\sqrt{ }$ & \\
\hline 2-methylpyrazine & $10^{-11}$ & $10^{-12}$ & $10^{-11}$ & $\sqrt{ }$ & $\sqrt{ }$ & $\sqrt{ }$ \\
\hline 2-ethylpyrazine & $10^{-11}$ & $10^{-12}$ & $10^{-12}$ & & $\sqrt{ }$ & \\
\hline 2,5-dimethylpyrazine & $10^{-11}$ & $10^{-8}$ & $10^{-9}$ & $\sqrt{ }$ & $\sqrt{ }$ & $\sqrt{ }$ \\
\hline 2,3,5-trimethylpyrazine & $10-10$ & $10^{-9}$ & $10^{-9}$ & $\sqrt{ }$ & $\sqrt{ }$ & $\sqrt{ }$ \\
\hline 2,6-dimethylpyrazine & $10-9$ & $10^{-6}$ & $10^{-7}$ & $\sqrt{ }$ & $\sqrt{ }$ & $\sqrt{ }$ \\
\hline \multicolumn{7}{|l|}{ PHENOLS, INDOLES, OTHERS } \\
\hline Indole & $10^{-14}$ & $10^{-13}$ & $10^{-15}$ & & $\sqrt{ }$ & \\
\hline Isoquinoline & $10^{-13}$ & $10^{-12}$ & $10^{-13}$ & & $\sqrt{ }$ & \\
\hline 4-Ethylphenol & $10^{-12}$ & $10^{-11}$ & $10^{-12}$ & $\sqrt{ }$ & $\sqrt{ }$ & \\
\hline Quinoline & $10-11$ & $10^{-13}$ & $10^{-11}$ & & $\sqrt{ }$ & \\
\hline 4-Methylphenol & $10^{-11}$ & $10^{-12}$ & $10^{-11}$ & $\sqrt{ }$ & $\sqrt{ }$ & \\
\hline 2-Methylphenol & $10-11$ & $10-9$ & $10^{-11}$ & $\sqrt{ }$ & $\sqrt{ }$ & \\
\hline 5-Methylindole & $10-11$ & $10^{-10}$ & $10^{-10}$ & & & \\
\hline 2,6-Dimethoxyphenol & $10^{-11}$ & $10^{-10}$ & $10^{-9}$ & & $\sqrt{ }$ & \\
\hline Hydroquinone & $10^{-10}$ & $10^{-10}$ & $10^{-10}$ & & & \\
\hline 3-Methyl-2-cylcopenten-I-one & $10-10$ & $10^{-7}$ & $10^{-10}$ & & & \\
\hline 2,4-Dimethylphenol & $10^{-10}$ & $10^{-9}$ & $10-9$ & & & \\
\hline 2-Methoxyphenol & $10^{-10}$ & $10^{-8}$ & $10^{-8}$ & & & \\
\hline 2-Cyclopenten-I-one & $10^{-9}$ & $10^{-7}$ & $10^{-9}$ & & & \\
\hline 4-Methoxyphenol & $10^{-8}$ & $10^{-7}$ & $10^{-7}$ & & & \\
\hline 2-Ethylphenol & $10^{-8}$ & $10^{-5}$ & $10^{-7}$ & & & \\
\hline 2,5-Dimethylphenol & $10^{-7}$ & $10^{-8}$ & $10^{-6}$ & & & \\
\hline Benzene & $10^{-7}$ & $10-8$ & $10^{-6}$ & & & \\
\hline Phenol & $10^{-2}$ & $10^{-1}$ & $10^{-2}$ & & $\sqrt{ }$ & \\
\hline
\end{tabular}

'Compiled from References 131, 132, and 135.

${ }^{2}$ LOAEL = Lowest observed adverse effect level in the oocyte pick-up rate, ciliary beat frequency, and muscle contractions assays.

${ }^{3}$ Chemicals known to be on the FEMA GRAS list. Others may also be on this list.

${ }^{4}$ Chemicals on the FDA EAFUS list (Everything Added to Food in the United States).

${ }^{5}$ Chemicals that are added to cigarettes by American tobacco companies.

${ }^{6}$ No effect at the highest dose tested. 
cific nitrosamines $[145,146]$, carbon monoxide $[147,148]$, tar [149-151], metals (cadmium, lead) $[152,153]$, and ten to fifteen other compounds including, phenol, acrolein, acetaldehyde, hydrogen cyanide, and formaldehyde [17,154-164]. Most of these chemicals have been linked to cancer or cardiovascular and lung disease. Of the 4,000 compounds found in cigarette smoke, at least 50 are known carcinogens [141]. PAHs and tobacco-specific $\mathrm{N}$-nitrosamines are major contributors to lung cancer $[154,161,165,166]$, while tar and carbon monoxide are major contributors to cardiovascular disease and chronic obstructive lung diseases $[161,163,167]$. PAHs have also been shown to initiate or promote atherosclerosis in avian [168-170] and mammalian [171] models. The PAH benzo(a)pyrene, induces atherosclerosis by stimulating proliferation of vascular smooth muscle cells that migrate into the vessel lumen $[172,173]$.

\section{(2) Chemicals in smoke that affect the oviduct}

Most of the above-mentioned chemicals that are commonly studied in smoke have not been studied with respect to their effects on the oviduct. An exception is nicotine, which did alter oviductal epithelium secretion and ion composition, embryo transport, embryo development, and oviductal blood flow in several in vivo studies (Section C1) and cumulus expansion in vitro [136].

\section{(a) Ciliotoxic chemicals}

Numerous studies have shown that cigarette smoke contains chemicals that are toxic to cilia of the mammalian respiratory system [174-178], the amphibian palate [179], Paramecium $[180,181]$, and the gills of mussels, clams, and mollusks $[182,183]$. Moreover, nicotine increased ciliary beat frequency in the ferret trachea [184], formaldehyde inhibited respiratory cilia in the rabbit and pig [185]; and hydrogen cyanide, acrolein, and acetaldehyde inhibited ciliary beating in the clam [182]. Using an in vitro infundibular bioassay, the individual smoke constituents, which had been previously shown to be ciliotoxic in non-oviductal systems $[175,176,182]$, were tested specifically for their effect on oviductal cilia [186]. Potassium cyanide (KCN), acrolein, phenol, acetaldehyde, and formaldehyde all inhibited ciliary beat frequency in a dose dependent manner in vitro [186]. However, only KCN was present in cigarette smoke solutions in a high enough concentration to account for the effect seen in vitro. KCN also inhibited oocyte pick-up rate. Nicotine did not inhibit ciliary beat frequency of the hamster oviduct, except at extremely high doses (Talbot, unpublished data).

\section{(b) Pyridines, pyrazines, and phenols}

Since cigarette smoke contains over 4000 compounds [17], there are likely other chemicals present in mainstream and sidestream cigarette smoke that can adversely affect oviductal functioning. To identify such chemicals, mainstream smoke solution from 2R1 cigarettes was fractionated by passage through 12 different solid phase extraction cartridges [77]. The eluates from each cartridge were screened using the hamster infundibular bioassay, and three cartridges were identified that retained inhibitory activity in the ciliary beat frequency, oocyte pick-up rate, and smooth muscle contraction bioassays. The chemicals in the eluates of each cartridge were then identified using GC-MS, and authentic standards of the identified compounds were purchased from commercial sources and tested independently to determine their activity in each of the three infundibular bioassays.

Pyridines, pyrazines, and phenols were the three major groups of chemicals identified in the inhibitory eluates (Table 1) $[77,131,132]$. Several other types of compounds including quinolines, indoles, and cyclopenten-1-ones were also present [132]. Within all groups, chemicals were identified that were highly inhibitory in all three bioassays, and some of the chemicals had LOAELs (lowest observed adverse effect levels) in the nano, pico and femtomolar range (Table 1). In general, if a chemical were inhibitory, it acted in all three bioassays, although the potency and efficacy for a particular chemical varied among the assays. Some of the compounds that were identified in this screen (Table 1 ) were previously thought to be safe and are included on the FEMA GRAS list (Flavor and Extract Manufacturers' Association - Generally Regarded $\underline{A} \underline{\text { Safe) }}$ ) and the FDA EAFUS list (Everything Added to Food in the United States). Some of these chemicals are added to tobacco to flavor it (Table 1). For example, 3-ethylpyridine, which was inhibitory in all three bioassays at picomolar doses, is on the list of 599 chemicals added to tobacco in the United States [187]. Of the seven pyrazines tested, six are on the FDA EAFUS list, and in all but three assays, the pyrazines had LOAELs in the nanomolar or picomolar range. Indole and isoquinoline were the most toxic of all chemicals tested with LOAELs in the femtomolar range, except for isoquinoline which had a picomolar LOAEL in the ciliary beat frequency assay.

Many of the compounds in Table 1 were also screened using a chick chorioallantoic membrane (CAM) assay that measures growth of the CAM and chick embryo $[188,189]$. In the CAM assay, many pyridines and pyrazines inhibited CAM growth dramatically, even at very low doses, and in some cases they also inhibited embryo growth. It is interesting that the chemicals in Table 1 were inhibitory in assays that measure diverse biological processes (ciliary beat frequency, oocyte pick-up, smooth muscle contraction, growth). It is not yet known if inhibition occurs by distinct mechanisms or if a basic underlying mechanism, such as inhibition of ATP production, was affected. Nor is it known if the chemicals act directly 
or indirectly, but given the extremely low effective doses of some of the chemicals, activation of a signaling cascade is possible.

These data from the oviduct and CAM studies indicate a need for further toxicological testing on the chemicals in Table 1, especially since some of them are used routinely in consumer products including food, cigarettes and cosmetics. These data also indicate a need for additional studies on the chemicals in smoke in general. The solid phase cartridge screen found about 40 oviductal toxicants, most of which were not previously recognized as smoke toxicants. It is probable that there are other toxicants in cigarette smoke that have not yet been identified as harmful nor studied in detail.

\section{E. Concentrations of smoke toxicants in cigarettes and in human smokers}

The data on oviductal toxicants beg the question - what are the concentrations of these compounds in cigarette smoke and in actual active and passive smokers? Some of the oviductal toxicants, such as nicotine, have been studied extensively, and concentrations are well documented in both cigarettes and smokers [17,190-192]. The LOAEL concentrations of 2-ethylpyridine, 2-methylpyridine, and 3 -ethylpyridine are about 10,000 to a million times lower than the concentration of these chemicals in mainstream and sidestream smoke from commercial cigarettes and cigars $[77,193]$. However, some of these toxicants, such as 3-ethylpyridine, have not previously been recognized as harmful, and little is known about their concentrations, in smokers. Many chemicals were inhibitory in the infundibular bioassays at nano and picomolar doses suggesting that they could be effective in vivo at extremely low doses that would be difficult to detect and measure. Concentrations of cigarette smoke components, such as phenolic compounds, vary among different brands of cigarettes [194]. For example, different types of cigarettes, such as Indian Bidi cigarettes, have higher concentrations of phenols than traditional commercial cigarettes [157]. Concentrations of chemicals also vary between various research brand cigarettes [195]. Finally, the source of the smoke also affects chemical concentration. While mainstream and sidestream smoke have similar chemicals the relative amounts of particular chemicals can vary significantly between the two types of smoke [17].

Cigarette smoke chemicals or their metabolites must gain access to the circulatory system and reach their target organs to exert their toxicity. Studies have measured nicotine, cotinine (a metabolite of nicotine), and other cigarette smoke components in reproductive tissues, although little is known about concentrations in the oviduct per se. Interestingly, levels of cigarette toxicants in reproductive tissues or fluids can be significantly higher than in serum.
For example, pregnant rabbits injected with tritiated nicotine had 5-11 times higher nicotine concentrations in uterine fluid than in plasma [196]. Both nicotine [197] and phenols [198] have been detected in the cervical fluid of smokers, and nicotine concentrations in the cervical fluid $(66-2620 \mathrm{ng} / \mathrm{ml})$ were significantly higher than in serum $(0.1-39 \mathrm{ng} / \mathrm{ml})$ [199].

Cigarette smoke components have also been detected in the follicular fluid of smokers $[200,201]$. Cotinine, a biomarker for smoke exposure, was higher in the follicular fluid of active smokers ( mean $=285.69 \mathrm{ng} / \mathrm{ml}$; range $=$ $62.21-595.00$ ) than passive smokers ( mean $=29.65 \mathrm{ng} /$ $\mathrm{ml}$; range $=20.91-45.75)$ and nonsmokers $($ mean $=3.71$ $\mathrm{ng} / \mathrm{ml}$; range $=1.20-15.62)$ [200]. Cadmium, like other smoke components, does reach and accumulate in the follicular fluid of smokers (7.93 ng/mL) [202], and cadmium concentration in the ovary was elevated in smokers $(150 \mathrm{ng} / \mathrm{g})$ versus nonsmokers $(115 \mathrm{ng} / \mathrm{g}$ ) [203]. While cadmium apparently does not interfere with embryo transport through the oviduct in the rat [204], it is another example of a smoke toxicant that can accumulate in reproductive organs and which, in laboratory animals, can adversely affect reproduction [205]. While many of the toxicants that affect the oviduct have not been quantified in smokers and there is little known about their concentrations in the oviduct, those chemicals that have been studied, appear to reach the reproductive organs and are often found in higher concentration in reproductive tissues and fluids than in serum or urine.

\section{F. Summary}

The oviduct, while seemingly a simple organ, is exquisitely designed to convey gametes in opposite directions virtually simultaneously and to provide a suitable environment for preimplantation development and transport of embryos to the uterus for implantation. It is vital for reproductive success. Factors that interfere with its functioning can adversely affect fertility. The oviduct serves as a useful model to evaluate the effect of cigarette smoke and its components on a reproductive organ and in a more general sense on a variety of biological functions. While most work on smoke's effect on the oviduct has been done on ciliary beat frequency, oocyte pick-up rate, cilia-oocyte cumulus complex adhesion, and smooth muscle contraction, other parameters of oviductal functioning could be added to this array of bioassays. For example, monitoring the synthesis and secretion of the oviductal proteins may give further insight into how smoke affects oviductal functioning and secretory processes in general. The oviductal assays have been useful in identifying numerous smoke toxicants many of which were not previously recognized as harmful and some of which are widely used in consumer products. Further studies on the safety of these chemicals are needed. Com- 
mercial brands of cigarettes contain toxicants capable of shutting down oviductal functions in vitro and interestingly sidestream smoke is often more inhibitory than mainstream smoke. Harm reduction cigarettes, while apparently reduced in carcinogens, still contain chemicals that impair basic biological processes including ciliary beating, oocyte pick-up, and smooth muscle contraction. The effects of smoke on the heart and lungs is widely known and well documented. The effects of smoke on the oviduct, which are just recently becoming more widely recognized, demonstrate that organs remote from the site of inhalation may be adversely affected by chemicals in smoke are consistent with the idea that all organs are targets of smoke [1]. Active and passive smokers of reproductive age should be made aware of the possible dangers in smoking and how smoking could affect their reproductive ability.

\section{Additional material}

\section{Additional File 1}

Video movie showing a stained oocyte cumulus complex (blue) being pickup by a hamster infundibulum. The complex adheres to the surface of the oviduct and is pulled along towards the ostium by ciliary beating. Reprinted from Molec Biol Cell 10:5-9, 1999 (with permission). Click here for file

[http://www.biomedcentral.com/content/supplementary/14777827-3-52-S1.mov]

\section{Additional File 2}

Video movies showing a control (right) and smoke treated infundibulum. The oocyte cumulus complex (blue) on the control oviduct moves over the surface of the infundibulum and is picked up at the normal rate. In the smoke exposed preparation, the oocyte cumulus complex barely moves during the same interval of time. Reprinted from Molec Biol Cell 10:5-9, 1999 (with permission).

Click here for file

[http://www.biomedcentral.com/content/supplementary/14777827-3-52-S2.mov]

\section{Acknowledgements}

We gratefully acknowledge the Tobacco-Related Disease Research Program of California which supported parts of the work reviewed in this article and our many associates who helped conduct the work. We are also grateful to Dr. Ray Talbot for his help in preparing the table.

\section{References}

I. The Health Consequences of Smoking: a Report of the Surgeon General. Atlanta, GA, Dept of Health and Human Services, Center for Disease Control, antional Center for Chronic Disease Preventation and Health Promotion, Office of Smoking and Health, Washington, DC; 2004.

2. Stillman RJ, Rosenberg MJ, Sachs BP: Smoking and Reproduction. Fertil and Sterility 1986, 46:545-566.

3. Atrash HK, Hughes JM, Hogue C: Ectopic pregnancy in the United States, 1970-1983. CDC Surveillence Summaries MMWR 1986, 35:29-37.
4. Stergachis A, Scholes D, Daling JR, Weiss NS, Chu J: Maternal cigarette smoking and the risk of tubal pregnancy. $A m$ J Epidemiology 1991, 133:322-337.

5. Augood C, Duckitt K, Templeton AA: Smoking and female infertility: a systematic review and meta-analysis [see comments]. Hum Reprod 1998, 13:1532-1539.

6. Saraiya M, Berg CJ, Kendrick JS, Strauss LT, Atrach HK, Ahn YW: Cigarette smoking as a risk factor for ectopic pregnancy. $\mathrm{Am}$ J Obstet Gynecol 1998, I 78:493-498.

7. Shiverick KT, Salafia C: Cigarette smoking and pregnancy I: ovarian, uterine and placental effects. Placenta 1999, 20:265-272.

8. Bouyer ]: [Epidemiology of ectopic pregnancy: incidence, risk factors and outcomes]. J Gynecol Obstet Biol Reprod (Paris) 2003, 32:S8-17.

9. Burguet A, Agnani G: Smoking, fertility and very preterm birth. Journal of Gynecology and Obstetric Biology of Reproduction 2003, 32:IS9-16.

10. Daling JR: Cigarette smoking and primary tubal infertility. In Smoking and Reproductive Health Edited by: MJ R. Littleton, MA, PSG Publishers; 1987:40-46.

II. Phipps WR, Cramer DW, Schiff I, Belisle S, Stillman R: The association between smoking and female infertility as influenced by cause of infertility. Sterility and Fertility 1987, 48:377-382.

12. Chow WH, Daling JR, Weiss NS: Maternal cigarette smoking and tubal pregnancy. Obstetrics and Gynecology 1988, 71:167-170.

13. Wald NJ, Hackshaw AK: Cigarette smoking: an epidemiological overview. Br Med Bull 1996, 52:3-II.

14. Munafo M, Murphy M, Whiteman D, Hey K: Does cigarette smoking increase time to conception? J Biosoc Sci 2002, 34:65-73.

15. Dekeyser-Boccara J, Milliez ]: [Smoking and ectopic pregnancy: is there a causal relationship?]. J Gynecol Obstet Biol Reprod (Paris) 2005, 34 Spec No I:3SI 19-23.

16. Baird DD, Wilcox A): Cigarette smoking associated with delayed conception. Jama 1985, 253:2979-2983.

17. EPA: EPA Report/600/6-90/006F: Respiratory health effects of passive smoking: lung cancer and other disorders. Washington, DC, ; 1992.

18. Misra DP, Nguyen RH: Environmental tobacco smoke and low birth weight: a hazard in the workplace? Environ Health Perspect 1999, 107 Suppl 6:897-904.

19. Windham GC, Eaton A, Hopkins B: Evidence for an association between environmental tobacco smoke exposure and birthweight: a meta-analysis and new data. Paediatr Perinat Epidemiol 1999, 13:35-57.

20. Windham GC, Von Behren J, Waller K, Fenster L: Exposure to environmental and mainstream tobacco smoke and risk of spontaneous abortion. Am J Epidemiol 1999, 149:243-247.

21. Andres RL, Day MC: Perinatal complications associated with maternal tobacco use. Semin Neonatol 2000, 5:23I-24I.

22. Hruba D, Kachlik $P$ : Influence of maternal active and passive smoking during pregnancy on birthweight in newborns. Cent Eur J Public Health 2000, 8:249-252.

23. Hull MG, North K, Taylor H, Farrow A, Ford WC: Delayed conception and active and passive smoking. The Avon Longitudinal Study of Pregnancy and Childhood Study Team. Fertil Steril 2000, 74:725-733.

24. Kukla L, Hruba D, Tyrlik M: Smoking and damages of reproduction: evidence of ELSPAC. Cent Eur J Public Health 200I, 9:59-63.

25. Mitchell EA, Thompson JM, Robinson E, Wild CJ, Becroft DM, Clark PM, Glavish N, Pattison NS, Pryor JE: Smoking, nicotine and tar and risk of small for gestational age babies. Acta Paediatr 2002, 91:323-328.

26. Dejmek J, Solansk y I, Podrazilova K, Sram RJ: The exposure of nonsmoking and smoking mothers to environmental tobacco smoke during different gestational phases and fetal growth. Environ Health Perspect 2002, I 1 0:601-606.

27. Berthiller ], Sasco AJ: [Smoking (active or passive) in relation to fertility, medically assisted procreation and pregnancy]. J Gynecol Obstet Biol Reprod (Paris) 2005, 34 Spec No I:3S47-54.

28. Kharrazi M, DeLorenze GN, Kaufman FL, Eskenazi B, Bernert JTJ, Graham S, Pearl M, Pirkle J: Environmental tobacco smoke and pregnancy outcome. Epidemiology 2004, 1 5:660-670.

29. Ojima T, Uehara R, Watanabe M, Tajimi M, Oki I, Nakamura Y: Population attributable fraction of smoking to low birth weight in Japan. Pediatr Int 2004, 46:264-267. 
30. Goel P, Radotra A, Singh I, Aggarwal A, Dua D: Effects of passive smoking on outcome in pregnancy. J Postgrad Med 2004, 50:12-16.

31. Neal MS, Hughes EG, Holloway AC, Foster WG: Sidestream smoking is equally as damaging as mainstream smoking on IVF outcomes. Hum Reprod 2005.

32. Smoking and infertility. Fertil Steril 2004, 8I: | |8I- I I86.

33. Ashmead GG: Smoking and pregnancy. J Matern Fetal Neonatal Med 2003, 14:297-304.

34. Higgins S: Smoking in pregnancy. Curr Opin Obstet Gynecol 2002, I4:|45-|5|.

35. Harper JK: Gamete and Zygote Transport. In The Physiology of Reproduction second edition. Edited by: Knobil E and Neill JD. New York, Raven Press; 1994:123-185.

36. Puikkinen $\mathrm{MO}$ : Oviductal function is critical for very early human life. Annals of Medicine 1995, 27:307-310.

37. Buhi WC, Alvarez IM, Kouba AJ: Oviductal regulation of fertilization and early embryonic development. Journal of Reproduction and Fertility 1997, 52:285-300.

38. Hunter $\mathrm{RH}$, Rodriguez-Martinez $\mathrm{H}$ : Capacitation of mammalian spermatozoa in vivo, with a specific focus on events in the Fallopian tubes. Mol Reprod Dev 2004, 67:243-250.

39. Hunter RH: Fallopian tube physiology: preliminaries to monospermic fertilization and cellular events post-fertilization. Ernst Schering Res Found Workshop 2005:245-26I.

40. Killian G]: Evidence for the role of oviduct secretions in sperm function, fertilization and embryo development. Animal Reproductive Science 2004, 82-83: |4 I-I53.

4I. Hunter RH: The Fallopian tubes in domestic mammals: how vital is their physiological activity? Reprod Nutr Dev 2005, 45:28I-290.

42. Suarez SS: Formation of a reservoir of sperm in the oviduct. Reproduction in Domestic Animals 2002, 37:|40-|43.

43. Croxatto HB: Physiology of gamete and embryo transport through the fallopian tube. Reprod Biomed Online 2002, 4:160-169.

44. Menezo Y, Guerin P: The mammalian oviduct: biochemistry and physiology. European Journal of Obstetrics, Gynecology, and Reproductive Biology 1997, 73:99-104.

45. Talbot $\mathrm{P}$, Geiske $\mathrm{C}, \mathrm{Knoll}$ M: Oocyte pick-up by the mammalian oviduct. Molec Biol Cell I999, I 0:5-8

46. Talbot $\mathrm{P}$, DiCarlantonio $\mathrm{G}$ : The oocyte-cumulus complex: ultrastructure of the extracellular components in hamsters and mice. Gam Res 1984, 10:127-142.

47. Yanagimachi R: Fertilization in mammals. Tokai J Exp Clin Med 1984, 9:81-85.

48. Motta PM, Nottola SA, Pereda J, Croxatto HB, Familiari G Ultrastructure of human cumulus oophorus: a transmission electron microscopic study on oviductal oocytes and fertilized eggs. Hum Reprod 1995, 10:236I-2367.

49. Ball GD, Bellin ME, Ax RL, First NL: Glycosaminoglycans in bovine cumulus-oocyte complexes: morphology and chemistry. Mol Cell Endocrinol 1982, 28: I I3-122.

50. Dandekar P, Aggelar J, Talbot P: Structure, distribution, and composition of the extracellular matrix of human oocytes and cumulus masses. Hum Reprod 1992, 7:391-398.

5I. Dandekar P, Talbot P: Perivitelline space of mammalian oocytes: extracellular matrix of unfertilized oocytes and formation of a cortical granule envelope following fertilization. Molec Reprod Develop 1992, 31:135-143.

52. Talbot P, DiCarlantonio G: Ultrastructure of opossum oocyte investing coats and their sensitivity to trypsin and hyaluronidase. Dev Biol 1984, 103:159-167.

53. Eppig J]: FSH stimulates hyaluronic acid synthesis by oocytecumulus cell complexes from mouse preovulatory follicles. Nature 1979, 28 I:483-484.

54. Eppig J]: Prostaglandin E2 stimulates cumulus expansion and hyaluronic acid synthesis by cumuli oophori isolated from mice. Biol Reprod 1981, 25:191-195.

55. Talbot P, Franklin LE: Hamster sperm hyaluronidase: I. A bioassay procedure based on cumulus dispersion rate. J Expt Zool 1974, 189:31|-320.

56. Chen L, Mao SJ, Larsen WJ: Identification of a factor in fetal bovine serum that stabilizes the cumulus extracellular matrix. A role for a member of the inter-alpha-trypsin inhibitor family. J Biol Chem I992, 267:I2380-I2386.
57. Chen L, Mao SJ, McLean LR, Powers RW, Larsen WJ: Proteins of the inter-alpha-trypsin inhibitor family stabilize the cumulus extracellular matrix through their direct binding with hyaluronic acid. I Biol Chem 1994, 269:28282-28287.

58. Hess KA, Chen L, Larsen WJ: Inter-alpha-inhibitor binding to hyaluronan in the cumulus extracellular matrix is required for optimal ovulation and development of mouse oocytes. Biol Reprod 1999, 6 I:436-443.

59. Carrette O, Nemade RV, Day AJ, Brickner A, Larsen WJ: TSG-6 is concentrated in the extracellular matrix of mouse cumulus oocyte complexes through hyaluronan and inter-alphainhibitor binding. Biol Reprod 2001, 65:30I-308.

60. Mukhopadhyay D, Hascall VC, Day AJ, Salustri A, Fulop C: Two distinct populations of tumor necrosis factor-stimulated gene6 protein in the extracellular matrix of expanded mouse cumulus cell-oocyte complexes. Arch Biochem Biophys 200I, 394: $173-18 \mid$

6I. Rugg MS, Willis AC, Mukhopadhyay D, Hascall VC, Fries E, Fulop C Milner CM, Day AJ: Characterization of complexes formed between TSG-6 and inter-alpha-inhibitor that act as intermediates in the covalent transfer of heavy chains onto hyaluronan. J Biol Chem 2005, 280:25674-25686.

62. Fulop C, Szanto S, Mukhopadhyay D, Bardos T, Kamath RV, Rugg MS, Day AJ, Salustri A, Hascall VC, Glant TT, Mikecz K: Impaired cumulus mucification and female sterility in tumor necrosis factor-induced protein-6 deficient mice. Development 2003 , | 30:2253-226 |.

63. Clewe TH, Mastroianni LJ: Mechanisms of ovum pickup. I. Functional capacity of rabbit oviducts ligated near the fimbria. Fertil Steril 1958, 9:13-17

64. Blandau R: Gamete transport - comparative aspects. In The Mammalian Oviduct Edited by: Hafez ESE and Blandau R. Chicago, University of Chicago Press; 1969:129-162.

65. Blandau $R$, Verdugo P. An overview of gamete transport - comparative aspects. In Ovum Tranport and Fertility Regulation Edited by: Harper MJK, J. PC, Adams CE, Coutinho EM and Paton DM. Copenhagen, Scriptor; 1976:138-I46.

66. Mahi-Brown CA, Yanagimachi R: Parameters influencing ovum pickup by oviductal fimbria in the golden hamster. Gam Res 1983, 8: I-10.

67. Norwood JT, Hein CE, Halbert SA, Anderson RGW: Polycationic macromolecules inhibit cilia-mediated ovum transport. Proc Natl Acad Sci 1978, 75:44I3-44I6.

68. Norwood JT, Anderson RGW: Evidence that adhesive sites on the tips of oviduct cilia membranes are required for ovum pickup in situ. Biol Reprod 1980, 23:788-79|.

69. Nakatani T, Shinohara H, Takeda S, Morisawa S, Matsuda T: Morphology of the intercapsular segment of the oviduct of the golden hamster with special reference to ovum-transit from ruptured follicles to the ampulla. Experientia 1985, 4l:368-370.

70. DiCarlantonio G, Shaoulian R, Knoll M, Magers T, Talbot P: Analysis of ciliary beat frequencies in hamster oviducal explants. J Exp Zool 1995, 272:142-152.

7I. Huang S, Driessen N, Knoll M, Talbot P: In vitro analysis of oocyte cumulus complex pick-up rate in the hamster Mesocricetus auratus. Molecular Reproduction and Development 1997, 47:312-322.

72. Lam X, Gieseke C, Knoll M, Talbot P: Assay and importance of adhesive interaction between hamster (Mesocricetus auratus) oocyte-cumulus complexes and the oviductal epithelium. Biol Reprod 2000, 62:579-588.

73. Talbot $P$, Shur BD, Myles DG: Cell adhesion and fertilization: steps in oocyte transport, sperm-zona pellucida interactions, and sperm-egg fusion. Biol Reprod 2003, 68: I-9.

74. Dirksen ER, Satir P: Ciliary activity in the mouse oviduct as studied by transmission and scanning electron microscopy. Tissue Cell 1972, 4:389-404.

75. Gordts S, Campo R, Romauts L, Brosen I: Endoscopic visualization of the process of fimbrial ovum retrieval in the human. Human Reproduction 1998, I3:|425-|428.

76. Halbert SA, Tam PY, Blandau RJ: Egg transport in the rabbit oviduct: the roles of cilia and muscle. Science 1976, I9 1:1052-1053.

77. Riveles K, Iv M, Arey J, Talbot P: Pyridines in cigarette smoke inhibit hamster oviductal functioning in picomolar doses. Reprod Toxicol 2003, 17:191-202. 
78. Gaddum-Rosse P, Blandau RJ: Comparative observations on ciliary currents in mammalian oviducts. Biol Reprod 1976, 14:605-609.

79. Suginami $\mathrm{H}$, Yano $\mathrm{K}$, Watanabe $\mathrm{K}$, Matsuura S: A factor inhibiting ovum capture by the oviductal fimbriae present in endometriosis peritoneal fluid. Fertil Steril I986, 46: I |40-I I 46.

80. Suginami $\mathrm{H}$, Yano $\mathrm{K}$ : An ovum capture inhibitor $(\mathrm{OCl})$ in endometriosis peritoneal fluid: an OCl-related membrane responsible for fimbrial failure of ovum capture. Fertil Steril 1988, 50:648-653.

81. Mastroianni LJ: The fallopian tube and reproductive health. Journal of Pediatric and Adolescent Gynecology 1999, 12:121-126.

82. Buhi WC, Alvarez IM, Kouba AJ: Secreted proteins of the oviduct. Cells Tissues Organs 2000, 166:165-179.

83. Suarez SS, Katz DF, Owen DH, Andrew JB, Powell RL: Evidence for the function of hyperactivated motility in sperm. Biol Reprod I991, 44:375-381.

84. Suarez SS, Ho HC: Hyperactivation of mammalian sperm. Cell Mol Biol (Noisy-le-grand) 2003, 49:35I-356.

85. McComb PF, Halbert SA, Gomel V: Pregnancy, ciliary transport, and the reversed ampullary segment of the rabbit fallopian tube. Fertil Steril 1980, 34:386-390.

86. McComb PF, Newman $\mathrm{H}$, Halbert SA: Reproduction in rabbits after excision of the oviductal isthmus, ampullary-isthmic junction, and uteroisthmic junction. Fertil Steril 1981, 36:669-677.

87. Ortiz ME, Bedregal P, Carajal MI, Croxatto HB: Fertilized and unfertilized ova are transported at different rates by the hamster oviduct. Biol Reprod 1986, 34:777-78I.

88. Velasquez LA, Aguilera JG, Croxatto HB: Possible role of plateletactivating factor in embryonic signaling during oviducta transport in the hamster. Biol Reprod 1995, 52:1302-1306.

89. Hermoso M, Barrera N, Morales B, Perez S, Villalon M: Platelet activating factor increases ciliary activity in the hamster oviduct through epithelial production of prostaglandin E2. Pflugers Arch 2001, 442:336-345.

90. Velasquez LA, Maisey K, Fernandez R, Valdes D, Cardenas H, Imara M, Delgado J, Aguilera J, Croxatto HB: PAF receptor and PAF acetylhydrolase expression in the endosalpinx of the human Fallopian tube: possible role of embryo-derived PAF in the control of embryo transport to the uterus. Hum Reprod 200I, I 6: I583-I 587

91. Ortiz ME, Llados C, Croxatto HB: Embryos of different ages transferred to the rat oviduct enter the uterus at different times. Biology of Reproduction 1989, 4I:38I-384.

92. Trejo CA, Navarro MC, Ambriz GD, Rosado A: Effect of maternal age and parity on preimplantation embryo development and transport in the golden hamster (Mesocricetus auratus). Lab Anim 2005, 39:290-297.

93. Halbert SA, Becker DR, Szal SE: Ovum transport in the rat oviductal ampulla in the absence of muscle contractility. Bio Reprod 1989, 40:II31-II36.

94. Woodruff JDPC): The Fallopian Tube. Baltimore, Williams and Williams; 1969.

95. Halbert SA, Tam PY, Adams RJ, Blandau RJ: An analysis of the mechanisms of egg transport in the ampulla of the rabbit oviduct. Gynecol Invest 1976, 7:306-320.

96. Bourdage RJ, Halbert SA: Quantification of intraluminal motion of surrogate ova in the rabbit oviductal isthmus. Biol Reprod 1984, 30: I I 24-1 I29.

97. Perez-Martinez S, Viggiano M, Franchi AM, Herrero MB, Ortiz ME, Gimeno MF, Villalon M: Effect of nitric oxide synthase inhibitors on ovum transport and oviductal smooth muscle activity in the rat oviduct. Journal of Reproduction and Fertility 2000 , I 18: III-117.

98. Bourdage RJ, Halbert SA: Distribution of embryos and 500microM microspheres in the rabbit oviduct: controls for acute motion analysis during transport. Biol Reprod 1988 , 38:282-29l.

99. Owman C, Rosenbren E, Sjoberg NO: Adrenergic innervation of the human female reproductive organs: a histochemical and chemical investigation. Obstet Gynecol 1967, 30:763-773.

100. Paton DM, Widdicombe JH, Rheaume DE, Johns A: The role of the adrenergic innervation of the oviduct in the regulation of mammalian ovum transport. Pharmacol Rev 1977, 29:67-102.
10I. Laszlo A, Nadasy GL, Monos E, Zsolnai B: Effect of pharmacological agents on the activity of the circular and longitudinal smooth muscle layers of human fallopian tube ampullar segments. Acta Physiol Hung 1988, 72: 123-133.

102. Samuelson UE, Sjostrand NO: Myogenic and neurogenic control of electrical and mechanical activity in human oviductal smooth muscle. Acta Physiol Scand 1986, 126:355-363.

103. Lindblom B, Hamberger L: Cyclic AMP and contractility of the human oviduct. Biology of Reproduction 1980, 22:173-I78.

104. Spilman $\mathrm{CH}$, Harper MJ: Effects of prostaglandins on oviductal motility and egg transport. Gynecologic Investigation 1975, 6:186-205.

105. Lindblom B, Hamberger L, Wiqvist N: Differentiated contractile effects of prostaglandins $E$ and $F$ on the isolated circular and longitudinal smooth muscle of the human oviduct. Fertil Steril 1978, 30:553-559.

106. Tan HN, Liu Y, Diao HL, Yang ZM: Cyclooxygenases and prostaglandin $E$ synthases in preimplantation mouse embryos. Zygote 2005, 13:103-108.

107. Arbab F, Goldsby J, Matijevic-Aleksic, Huang G, Ruan KH, Huang JC: Prostacyclin is an autocrine regulator in the contraction of oviductal smooth muscle. Human Reproduction 2002, 17:3063-3059.

108. Ekerhovd E, Brannstrom M, Weijdegard B, Norstrom A: Localization of nitric oxide synthase and effects of nitric oxide donors on the human Fallopian tube. Mol Hum Reprod 1999, 5:1040-1047.

109. Ekerhovd E, Brannstrom M, Alexandersson M, Norstrom A: Evidence for nitric oxide mediation of contractile activity in isolated strips of the human Fallopian tube. Hum Reprod 1997, 1 2:301-305.

I 10. Priyadarsana M, Wijayagunawardane B, Miyamoto A: Endothelin-I system in the bovine oviduct: a regulator of local contraction and gamete transport. J Cardiovasc Pharmacol 2004, 44 Suppl I:S248-5 I.

III. Wijayagunawardane MP, Miyamoto A, Taquahashi Y, Acosta T], Nishimura M, Sato K: Angiotensin II and atrial natriuretic peptide in the cow oviductal contraction in vitro: direct effect and local secretion of prostaglandins, endothelin-I, and angiotensin II. Biol Reprod 200I, 65:799-804.

I I2. Wang H, Guo Y, Wang D, Kingsley PJ, Marnett LJ, Das SK, DuBois RN, Dey SK: Aberrant cannabinoid signaling impairs oviductal transport of embryos. Nat Med 2004, 10:1074-1080.

1 13. Paria BC, Huet-Hudson YM, Dey SK: Blastocyst's state of activity determines the "window" of implantation in the receptive mouse uterus. Proc Natl Acad Sci U S A 1993, 90:10159-10162.

114. Carson DD, Bagchi I, Dey SK, Enders AC, Fazleabas AT, Lessey BA, Yoshinaga K: Embryo implantation. Dev Biol 2000, 223:217-237.

115. Cummings AM, Perreault SD: Methoxychlor accelerates embryo transport through the rat reproductive tract. Toxicol Appl Pharmacol 1990, 102:110-116.

116. Coutinho EM, Maia H, Nascimento L: The response of the human Fallopian tube to ergonovine and methyl-ergonovine in vivo. Am J Obstet Gynecol 1976, 1 26:48-54.

117. Neri A, Eckerling B: Influence of smoking and adrenaline (epinephrine) on the uterotubal insufflation test (Rubin test). Fertil Steril 1969, 20:8I8-828.

I 18. Ruckebusch Y: Relationship between the electrical activity of the oviduct and the uterus of the rabbit in vivo. I Reprod Fertil 1975, 45:73-82.

119. Magers T, Talbot P, DiCarlantonio G, Knoll M, Demers D, Tsai I, Hoodbhoy T: Cigarette smoke inhalation affects the reproductive system of female hamsters. Reprod Toxicol 1995, 9:513-525.

120. DiCarlantonio G, Talbot $P$ : Inhalation of mainstream and sidestream cigarette smoke retards embryo transport and slows muscle contraction in oviducts of hamsters (Mesocricetus auratus). Biol Reprod 1999, 61:65I-656

121. Jin Z, Jin M, Nilsson BO, Roomans GM: Effects of nicotine administration on elemental concentrations in mouse granulosa cells, maturing oocytes and oviduct epithelium studied by $X$ ray microanalysis. Journal of Submicroscopic Cytology and Pathology 1998, 30:517-520.

122. Rice C, Yoshinaga K: Effect of nicotine on oviducal lactate dehydrogenase during early pregnancy in the rat. Biol Reprod 1980 , 23:445-45I. 
123. Yoshinaga K, Rice C, Krenn J, Pilot CL: Effects of nicotine on early pregnancy in the rat. Biol Reprod 1979, 20:294-303.

124. Mitchell JH, Hammer RE: Effects of nicotine on oviducal blood flow and embryo development in the rat. J Reprod Fertil 1985, 74:7I-

125. Garcia-Pascual A, Labadia A, Triguero D, Costa G: Local regulation of oviductal blood flow. General Pharmacology 1996, 27:1303-1310.

126. Neri A, Marcus SL: Effect of nicotine on the motility of the oviducts in the Rhesus monkey: a preliminary report. J Reproduction Fertility 1972, 31:91-

127. Chung PH, Yeko TR, Mayer JC, Clark B, Welden SW, Maroulis GB: Gamete intrafallopian transfer. Does smoking play a role? J Reprod Med 1997, 42:65-70.

I28. Knoll M, Shaoulian R, Magers T, Talbot P: Ciliary beat frequency of hamster oviducts is decreased in vitro by exposure to solutions of mainstream and sidestream cigarette smoke. Biol Reprod 1995, 53:29-37.

129. Knoll M, Talbot P: Cigarette smoke inhibits oocyte cumulus complex pick-up by the oviduct independent of ciliary beat frequency. Reproductive Toxicology 1998, I 2:57-68.

130. Riveles K, Roza R, Kwan D, Talbot P: Pyridines that inhibit diverse biological processes are more concentrated in sidestream than mainstream smoke solutions from commercial cigarettes: ; Allergan, Irvine, Califoronia. ; 2003.

131. Riveles K, Roza R, Arey J, Talbot P: Pyrazine derivatives in cigarette smoke inhibit hamster oviductal functioning. Reprod Biol Endocrinol 2004, 2:23.

132. Riveles K, Roza R, Talbot P: Phenols, Quinolines, Indoles, Benzene, and 2-Cyclopenten-I-ones are Oviductal Toxicants in Cigarette Smoke. Toxicol Sci 2005.

133. Gieseke C, Talbot P: Cigarette Smoke Inhibits Hamster Oocyte Pickup by Increasing Adhesion Between the Oocyte Cumulus Complex and Oviductal Cilia. Biol Reprod 2005.

134. Riveles K: Identification and Quantification of Toxicants in Mainstream and Sidestream Smoke that Affect Hamster Oviductal Functioning. In Interdepartmental Graduate Program in Environmental Toxicology Riverside, University of California; 2004.

135. Breland $A B$, Acosta MC, Eissenberg $T$ : Tobacco specific nitrosamines and potential reduced exposure products for smokers: a preliminary evaluation of Advance. Tob Control 2003, 12:317-321.

136. Vrsanska S, Nagyova E, Mlynarcikova A, Fickova M, Kolena J: Components of cigarette smoke inhibit expansion of oocytecumulus complexes from porcine follicles. Physiological Research 2003, 52:383-387.

137. Kalman D: The subjective effects of nicotine: methodological issues, a review of experimental studies, and recommendations for future research. Nicotine Tob Res 2002, 4:25-70.

138. Yoshimasu K, Kiyohara C: Genetic influences on smoking behavior and nicotine dependence: a review. J Epidemiol 2003, 13:183-192.

139. Le Houezec J: Role of nicotine pharmacokinetics in nicotine addiction and nicotine replacement therapy: a review. Int J Tuberc Lung Dis 2003, 7:81 I-819.

140. Adams JD, Lee S], Hoffmann D: Carcinogenic agents in cigarette smoke and the influence of nitrate on their formation. Carcinogenesis 1984, 5:221-223.

|4l. Smith CJ, Livingston SD, Doolittle DJ: An international literature survey of "IARC group I carcinogens" reported in mainstream cigarette smoke. Food and Chemical Toxicology 1997, 35: $1107-1130$.

142. Zedeck MS: Polycyclic aromatic hydrocarbons: a review. J Environ Pathol Toxicol I 980, 3:537-567.

143. Santodonato J: Review of the estrogenic and antiestrogenic activity of polycyclic aromatic hydrocarbons: relationship to carcinogenicity. Chemosphere 1997, 34:835-848.

144. Besarati Nia A, Kleinjans JC, Van Schooten FJ: Biomonitoring of tobacco smoke carcinogenicity by dosimetry of DNA adducts and genotyping and phenotyping of biotransformational enzymes: a review on polycyclic aromatic hydrocarbons. Biomarkers 2002, 7:209-229.

145. Wu W, Ashley DL, Watson CH: Simultaneous determination of five tobacco-specific nitrosamines in mainstream cigarette smoke by isotope dilution liquid chromatography/electro- spray ionization tandem mass spectrometry. Anal Chem 2003 , 75:4827-4832.

146. Stepanov I, Hecht SS: Tobacco-specific nitrosamines and their pyridine- $\mathbf{N}$-glucuronides in the urine of smokers and smokeless tobacco users. Cancer Epidemiol Biomarkers Prev 2005, | 4:885-89|.

147. Benowitz NL, Jacob P: Effects of cigarette smoking and carbon monoxide on nicotine and cotinine metabolism. Clin Pharmacol Ther 2000, 67:653-659.

148. Zevin S, Saunders S, Gourlay SG, Jacob P, Benowitz NL: Cardiovascular effects of carbon monoxide and cigarette smoking. J Am Coll Cardiol 200I, 38:1633-1638.

149. Eke BC, Iscan M: Effects of cigarette smoke with different tar contents on hepatic and pulmonary xenobiotic metabolizing enzymes in rats. Hum Exp Toxicol 2002, 21 : 17-23.

150. Foy JW, Bombick BR, Bombick DW, Doolittle DJ, Mosberg AT, Swauger JE: A comparison of in vitro toxicities of cigarette smoke condensate from Eclipse cigarettes and four commercially available ultra low-"tar" cigarettes. Food Chem Toxicol 2004, 42:237-243.

15I. Harris JE, Thun MJ, Mondul AM, Calle EE: Cigarette tar yields in relation to mortality from lung cancer in the cancer prevention study II prospective cohort, 1 982-8. Bmj 2004, 328:72.

152. Jenkins RA: Occurrence of selected metals in cigarette tobaccos and smoke. IARC Sci Publ 1986:129-138.

153. Ronco AM, Arguello G, Munoz L, Gras N, Llanos M: Metals content in placentas from moderate cigarette consumers: correlation with newborn birth weight. Biometals 2005, I 8:233-24 I.

154. Wynder EL, Hoffmann D: Experimental tobacco carcinogenesis. Science 1968, 162:862-871.

I55. Wynder EL, Hoffmann D: A study of tobacco carcinogenesis. Cancer 1969, 24:289-30I.

156. Hoffmann D, Bondinell WE, Wynder EL: Carcinogenicity of methylchrysenes. Science 1974, I 83:215-216.

157. Hoffmann D, Adams JD, Brunnemann KD, Hecht SS: Assessment of tobacco-specific $\mathbf{N}$-nitrosamines in tobacco products. Cancer Res 1979, 39:2505-2509.

158. Anderson LM, Hecht SS, Dixon DE, Dove LF, Kovatch RM, Amin S, Hoffmann D, Rice JM: Evaluation of the transplacental tumorigenicity of the tobacco-specific carcinogen 4-(methylnitrosamino)-I-(3-pyridyl)-I-butanone in mice. Cancer Research 1989, 49:3770-3775

159. Risner $\mathrm{CH}$, Martin P: Quantitation of formaldehyde, acetaldehyde, and acetone in sidestream cigarette smoke by highperformance liquid chromatography. I Chromatogr Sci 1994, 32:76-82.

160. Hoffmann D, Djordjevic MV, Hoffmann I: The changing cigarette. Preventive Medicine 1997, 26:437-434.

16I. Rodgman A, Smith CJ, Perfetti TA: The composition of cigarette smoke: a retrospective, with emphasis on polycyclic components. Human and Experimental Toxicology 2000, 19:573-595.

162. Smith C], Hansch C: The relative toxicity of compounds in mainstream cigarette smoke condensate. Food and Chemical Toxicology 2000, 38:637-646.

163. Pfeifer GP, Denissenko MF, Olivier M, Tretyakova N, Hecht SS, Hainaut P: Tobacco smoke carcinogens, DNA damage and p53 mutations in smoking-associated cancers. Oncogene 2002, 2 I:7435-745I.

164. Hoffmann D, Raineri R, Hecht SS, Maronpot R, Wynder EL: A study of tobacco carcinogenesis. XIV. Effects of N'nitrosonornicotine and $\mathbf{N}^{\prime}$-nitrosoanabasine in rats. Journal of the National Cancer Institute 1975, 55:977-979.

165. Hoffmann D, Rivenson A, Hecht SS: The biological significance of tobacco-specific $\mathbf{N}$-nitrosamines: smoking and adenocarcinoma of the lung. Critical Reviews in Toxicology I996, 26:199-2 I I.

166. Nordskog BK, Blixt AD, Morgan WT, Fields WR, Hellmann GM: Matrix-degrading and pro-inflammatory changes in human vascular endothelial cells exposed to cigarette smoke condensate. Cardiovascular Toxicology 2003, 3: 101-I I7.

167. Bond JA, Gown AM, Yang HL, Benditt EP, Juchau MR: Further investigations of the capacity of polynuclear aromatic hydrocarbons to elicit atherosclerotic lesions. I Toxicol Environ Health I981, 7:327-335.

168. Hough JL, Baird MB, Sfeir GT, Pacini CS, Darrow D, Wheelock C: Benzo(a)pyrene enhances atherosclerosis in White Carneau and Show Racer pigeons. Arterioscler Thromb 1993, I 3:1721-I 727. 
169. Batastini G, Penn A: An ultrastructural comparison of carcinogen-associated and spontaneous aortic lesions in the cockerel. Am J Pathol 1984, I | 4:403-409.

170. Cox LR, Ramos K: Allylamine-induced phenotypic modulation of aortic smooth muscle cells. J Exp Pathol (Oxford) 1990, 7I:II-18.

I7I. Ramos KS, Parrish AR: Growth-related signaling as a target of toxic insult in vascular smooth muscle cells: implications in atherogenesis. Life Sci 1995, 57:627-635.

172. Ou X, Ramos KS: Proliferative responses of quail aortic smooth muscle cells to benzo[a]pyrene: implications in PAH-induced atherogenesis. Toxicology 1992, 74:243-258.

173. Ballenger JJ: Experimental effect of cigarette smoke on human respiratory cilia. The New England Journal of Medicine 1960, 263:832-835.

174. Battista SP: Cilia toxic components of cigarette smoke. Volume \# (NIH) 76-I22I. Edited by: Wynder EL, Hoffman D and Gori GB. DHEW; 1974:5।7-534.

175. Dalhamm $\mathrm{T}$ : In vivo and in viro ciliotoxic effects of tobacco smoke. Arch Environ Health 1970, 21:633-634.

176. Pettersson B, Curvall $M$, Enzell $C$ : The inhibitory effect of tobacco smoke compounds on ciliary activity. European Journal of Respiratory Diseases 1985, I 39:89-92.

177. Stanley PJ, Wilson R, Greenstone MA, MacWilliam L, Cole PJ: Effect of cigarette smoking on nasal mucociliary clearance and ciliary beat frequency. Thorax 1986, 4I:519-523.

178. Zayas JG, O'Brien DW, Tai S, Ding J, Lim L, King M: Adaptation of an amphibian mucociliary clearance model to evaluate early effects of tobacco smoke exposure. Respir Res 2004, 5:9.

179. Wang H: Differential responses of Paramecium aurelia to cigarette smoke. Nature 1963, 197:946-948.

180. Weiss W, Weiss WA: Effect of tobacco smoke solutions on Paramecium. Arch Env Health 1964, 9:500-504.

I8I. Walker TR, Kiefer JE: Ciliastatic components in the gas phase of cigarette smoke. Science 1966, I 53: I 248-I 250.

182. Wynder EL, Goodman DA, Hoffmann D: Ciliatoxic components in cigarette smoke. 3 . In vitro comparison of different smoke components. Cancer 1965, I 8: I652-1658.

183. Hahn HL, Kleinchrot D, Hansen D: Nicotine increases ciliary beat frequency by a direct effect on respiratory cilia. Clinical Investigator 1992, 70:244-25I.

I84. Hastie AT, Patrick H, Fish JE: Inhibition and recovery of mammalian respiratory ciliary function after formaldehyde exposure. Toxicology anbd applied pharmacology 1990, 102:282-291.

185. Talbot $P$, DiCarlantonio $G$, Knoll $M$ : Identification of cigarette smoke components that alter functioning of hamster (Mesocricetus auratus) oviducts in vitro. Biol Reprod 1998, 58:1047-1053.

186. About: http://quitsmoking.about.com/od/cigaretteingredients/. 2004

I87. Ji L, Melkonian G, Riveles K, Talbot P: Identification of pyridine compounds in cigarette smoke solution that inhibit growth of the chick chorioallantoic membrane. Toxicological Sciences 2002, 69:217-225.

188. Melkonian G, Lautenschlager H, Wu M, Wang Y, Tong C, Riveles K, Talbot P: Growth and angiogenesis are inhibited in developing tissues by pyrazine and its derivatives. Toxicological Sciences 2003, 74:393-401:.

189. Armitage AK, Dolery CT, Houseman TH, Lewis PJ, Turner DM: Absorption and metabolism of nicotine from cigarettes. $\mathrm{Br}$ Med L 1975, 4:313-316.

190. Russel MAH, Jarvis M, Feyerbend C: Relation of nicotine yield of cigarettes to blood nicotine concentration in smokers. British Medical Journal 1980, 280:972-976.

19I. Kogen MJ, Verebey K, Jaffee JH, Mule SJ: Simultaneous determination of nicotine and cotinine in human plasma by nitrogen detection gas-liquid chromaography. I Forensic Sci 198I, 26:6-II.

192. Brunneman KD, Stahnke G, Hoffman D: Chemical studies on tobacco smoke. LXI. Volatile pyridines:quantitative analysis in mainstream and sidestream smoke of cigarettes and cigars. Analytical Letters 1978, A I I:545-560.

193. Nanni EJ, Lovette ME, Hicks RD, Fowler KW, Borgerding MF: Separation and quantitation of phenolic compounds in mainstream cigarette smoke by capillary gas chromatography with mass spectrometry in the selected-ion mode. Journal of Chromatography 1990, 505:365-374.

194. Forehand JB, Dooly GL, Moldoveanu SC: Analysis of polycyclic aromatic hydrocarbons, phenols and aromatic amines in particulate phase cigarette smoke using simultaneous distillation and extraction as a sole sample clean-up step. J Chromatogr A 2000, 898: I I I-I 24.

195. McLachlan JA, Dames NM, Sieber SM, Fabro S: Accumulation of nicotine in the uterine fluid of the six-day pregnant rabbit. Fertil Steril 1976, 27:1204-1213.

196. McCann MF, Irwin DE, Walton LA, Hulka BS, Morton JL, Axelrad CM: Nicotine and cotinine in the cervical mucus of smokers, passive smokers, and nonsmokers. Cancer Epidemiol Biomarkers Prev 1992, I:125-129.

197. Melikian AA, Sun P, Prokopczyk B, El-Bayoumy K, Hoffmann D, Wang $X$, Waggoner $S$ : Identification of benzo(a)pyrene metabolites in cervical mucus and DNA adducts in cervical tissues in humans by gas chromatography-mass spectrometry. Cancer Letters 1999, 146:127-134.

198. Sasson IM, Haley NJ, Hoffmann D, Wynder EL: Cigarette smoking and neoplasia of the uterine cervix: smoke constituents in cervical mucus. The New England Journal of Medicine 1985, 8| 2:315-3|6

199. Paszkowski T: Concentration gradient of cotinine between blood serum and preovulatory follicular fluid. Ginekol Pol 1998 , 69: $1131-1136$.

200. Zenzes MT, Reed TE, Wang P, Klein J: Cotinine, a major metabolite of nicotine, is detectable in follicular fluids of passive smokers in in vitro fertilization therapy. Fertil Steril 1996, 66:614-619.

20I. Zenzes NT, Krishnan S, Krishnan B, Zhang H, Casper RF: Cadmium accumulation in follicular fluid of women in in vitro fertilization-embryo transfer is higher in smokers. Fertility and Sterility 1995, 64:599-603.

202. Varga B, Zsolnai B, Paksy K, Naray M, Ungvary G: Age dependent accumulation of cadmium in the human ovary. Reproductive Toxicology 1993, 7:225-228.

203. Paksy K, Varga B, Naray M, Olajos F, Folly G: Altered ovarian progesterone secretion induced by cadmium fails to interfere with embryo transport in the oviduct of the rat. Reprod Toxicol 1992, 6:77-83.

204. Watanabe T, Shimada T, Endo A: Mutagenic effects of cadmium on mammalian oocyte chromosomes. Mutation Research 1979 , 67:349-356
Publish with Biomed Central and every scientist can read your work free of charge

"BioMed Central will be the most significant development for disseminating the results of biomedical research in our lifetime. "

Sir Paul Nurse, Cancer Research UK

Your research papers will be:

- available free of charge to the entire biomedical community

- peer reviewed and published immediately upon acceptance

- cited in PubMed and archived on PubMed Central

- yours - you keep the copyright
BioMedcentral 